\title{
Seasonality and Dynamic Spatial Contagion of Air Pollution in 42 Chinese Cities
}

\author{
Zhanqiong He, ${ }^{1,2}$ Songsak Sriboonchita, ${ }^{2}$ and ${\mathrm{Min} \mathrm{He}^{3}}^{3}$ \\ ${ }^{1}$ Faculty of Management and Economics, Lianhua Campus, Kunming University of Science and Technology, Kunming 650093, China \\ ${ }^{2}$ Faculty of Economics, Chiang Mai University, Chiang Mai 50200, Thailand \\ ${ }^{3}$ Faculty of Transportation Engineering, Chenggong Campus, Kunming University of Science and Technology, Kunming 650504, China
}

Correspondence should be addressed to Min He; kmhemin@gmail.com

Received 30 November 2012; Accepted 24 December 2012

Academic Editors: S. Bhattacharya and N. Fontanals

Copyright (C) 2013 Zhanqiong He et al. This is an open access article distributed under the Creative Commons Attribution License, which permits unrestricted use, distribution, and reproduction in any medium, provided the original work is properly cited.

To monitor and improve the urban air quality, the Chinese government has begun to make many efforts, and the interregional cooperation to cut and improve air quality has been required. In this paper, we focus on the seasonality of the first and second moments of the daily air pollution indexes (APIs) of 42 Chinese sample cities over 10 years, from June 5, 2000 to March 4, 2010, and investigate the dynamic correlation of air pollution indexes (APIs) between 42 Chinese cities and their corresponding regional and national levels; comparison with the model without seasonal consideration is made. By adopting a DCC-GARCH model that accounts for the seasonality, we found that (i) the transformed DCC-GARCH model including seasonality dummies improves the estimation result in this study; (ii) the seasonality feature of the second moment follows that of the first moment, with the condition mean and variance of the second and autumn significantly lower than spring, whereas that of winter is higher than spring; (iii) the correlation between local APIs and their corresponding regional and national levels is dynamic; (iv) comparing with the DCCGARCH model estimation, the transformed model does not change the feature of the dynamic correlations very much.

\section{Introduction}

With the increasing concern of environmental problem and public health, Chinese government began to struggle the urban air quality problem. Many efforts have been made by the national and local authorities. Some cities began to restrict the car ownership; policies encouraging low-carbon economy are established and implemented. Moreover, the interregional cooperation to cut and improve air quality has been required. The three key regions required to carry out the interregional cooperation are in northern China which includes Beijing, Tianjin, and Hebei; Yangtze River Delta; Pearl River Delta. The three regions are the most developed and populated ones. Their cooperation seems more urgent, and their cooperation will provide experiences for other, regional kinds of and national cooperation. As a big country with wide territory, investigating more sample cities is necessary, since it will provide more information for further research and policy decision.
Air quality is a public good that generates transboundary spillovers. Cooperation between cities, regions, or even countries is very important. Good understanding of spatial contagion is very important for the air pollution control cooperation. So, it is important to study the dynamic correlations between local, regional, and national levels, by then providing support for intraregional, interregion, and national cooperation.

Some previous studies have surveyed the regional nature of the air pollution. Miller and Grumet [1] provide an overview of the scientific basis that supports the actions of the USA and Canada to implement regional ozone pollution control measures. Cousin et al. [2] studied the synoptic and local meteorological situation in the Marseille region, Europe, and found that ozone levels are due to both regional and local factors. By using a time series, cross-sectional panel of pollution data from Hong Kong and southern China, along with weather variables from Hong Kong and employing an econometrically-based structural model, Xiao et al. [3] 
TABLE 1: Cities of study and corresponding regions.

\begin{tabular}{lc}
\hline Region & Cities \\
\hline $\begin{array}{l}\text { Central China } \\
\text { Easernt China } \\
\text { Northern China } \\
\text { Northeast }\end{array}$ & Changsha, Hefei, Nanchang, Wuhan, and Zhenzhou \\
Northwest & Hangzhou, Jinan, Nanjing, Nantong, Qingdao, Shanghai, Suzhou, Wenzhou, and Yantai \\
Qinghai-Tibet & Beijing, Huhehaote, Shijiazhuang, Taiyuan, and Tianjin \\
Southern China & Changchun, Dalian, Haerbin, and Shenyang \\
Southeast & Lanzhou, Wulumuqi, Xian, and Yinchuan \\
Southwest & Lasa and Xining \\
\hline
\end{tabular}

conducted Granger causality tests and found that pollutants PM10 and $\mathrm{NO}_{2}$ causality runs in both directions, which confirmed the regional nature of the air pollution problem.

More studies focus on the impact of emission or dust from one region to another. Zhang et al. [4] examined the impact of tripled anthropogenic emissions from China and India over the base level (gaseous species and carbonaceous aerosols for 2000) on air quality over the USA. The simulations indicate an extensive area of elevated pollutant concentrations spanning from the Arabian Sea to the Northern Pacific and to the northern Atlantic. Holloway et al. [5] studied the geographic variability and seasonality of the inflow of global pollutants to Asia. They found that imported $\mathrm{O}_{3}$ contributes significantly throughout Asia. In detail, both North America and Europe contribute to ground-level $\mathrm{O}_{3}$ concentrations throughout the region, though the seasonality of these two sources varies. Based on aluminium and calcium concentrations in PM10, Lee et al. [6] studied the transport of dusts from east Asian and noneast Asian sources to Hong Kong and found that dust events (96\%) involve noneast Asian sources. Liu et al. [7] studied the influence of Asian dust storms on air quality in Taiwan. The high PM10 concentration on the east coast is associated with long-range transported dust, but the high PM10 concentration at the western side is due to a mixture of dust particles and local pollutants.

Seasonality is another focus of former researches. Zhang et al. [8] found that total suspended particle (TSP) was the chief pollutant influencing air pollution index (API) in northern China in spring and winter seasons. Sand and dust storm might be a major factor affecting the temporal variability and spatial distribution of TSP and dust fall in China. Grivas et al. [9] analyzed PM10 concentration data collected at 8 sites over the Greater Athens. Statistical examination showed that the seasonal variation of PM10 levels was not found to be uniform across the 8 sites, and significant intersite correlations were observed. Yamaji et al. [10] analyzed the seasonal variation of surface $\mathrm{O}_{3}$ over Japan. They concluded that surface $\mathrm{O}_{3}$ distribution over East Asia varies dynamically from season to season according to the meteorological condition, with $\mathrm{O}_{3}$ concentrations characterized by two peaks in spring and autumn and summer minimum. Fang and Chang [11] analyzed atmospheric particulate (PM10 and PM2.5) mass concentration using hourly data collected from seven air quality monitoring stations in Taiwan and found that the highest mean PM2.5 particle concentration was detected during spring, whereas the highest mean PM2.5 particle concentration was recorded during winter. By selecting 4 sites covering urban, suburban, rural, and coastal areas as representatives for detailed analysis, Zheng et al. [12] analyzed Pearl River Delta (PRD) regional air quality monitoring network and investigated the characteristics of ground-level ozone in the region. Their results showed that there are distinct seasonal and diurnal cycles in ground-level ozone across the PRD region. Chan [13] investigated the seasonal variation of different types of particulates in a fixed roadside station in heavily trafficked urban area of Hong Kong. They found that large-size particles had an apparent seasonal variation, with higher concentration level in winter and lower in summer. The dry continental winter monsoon and the wet oceanic summer monsoon are the dominating factors. On the other hand, the variation of PM2.5 is much smaller since they are more affected by local traffic emission. So et al. [14] studied long-term trend and spatial variations of PM2.5 mass and chemical composition in Hong Kong covering 3 sites with different land-use characteristics, namely, roadside, urban, and rural environments. They found that seasonal variations of PM2.5 mass concentration at the 3 sites were similar higher in autumn/winter and lower in summer. Hoti et al. [15] analyzed the trends and volatility in atmospheric carbon dioxide concentration levels using daily data from January 11991 to December 312002 collected at Ryori, Japan, and Mauna Loa, USA. Their results implied that the two regions, namely, Asia and the southwest Pacific, were independent in terms of the shocks to the ACDC levels. Using hourly data of PM10 concentration, Yang [16] evaluated the spatial and seasonal variations in the four regions in Taiwan, and they found that spatial and seasonal variations of PM10 concentrations are rather large over Taiwan; seasonal variation is characterized by high concentrations in winter and low in summer. Gupta et al. [17] investigated the air quality of urban region of Kolkata, India, consisting of residential, commercial, and industrial sites having high population density and pollution. Winter concentrations of ambient $\mathrm{SO}_{2}, \mathrm{NO}_{2}, \mathrm{NH}_{3}$, and PM10 were observed to be higher irrespective of the monitoring sites.

The past literature revealed that most studies focusing on the relationship between regions have focused on the impact of emission or dust from one region to another, and 


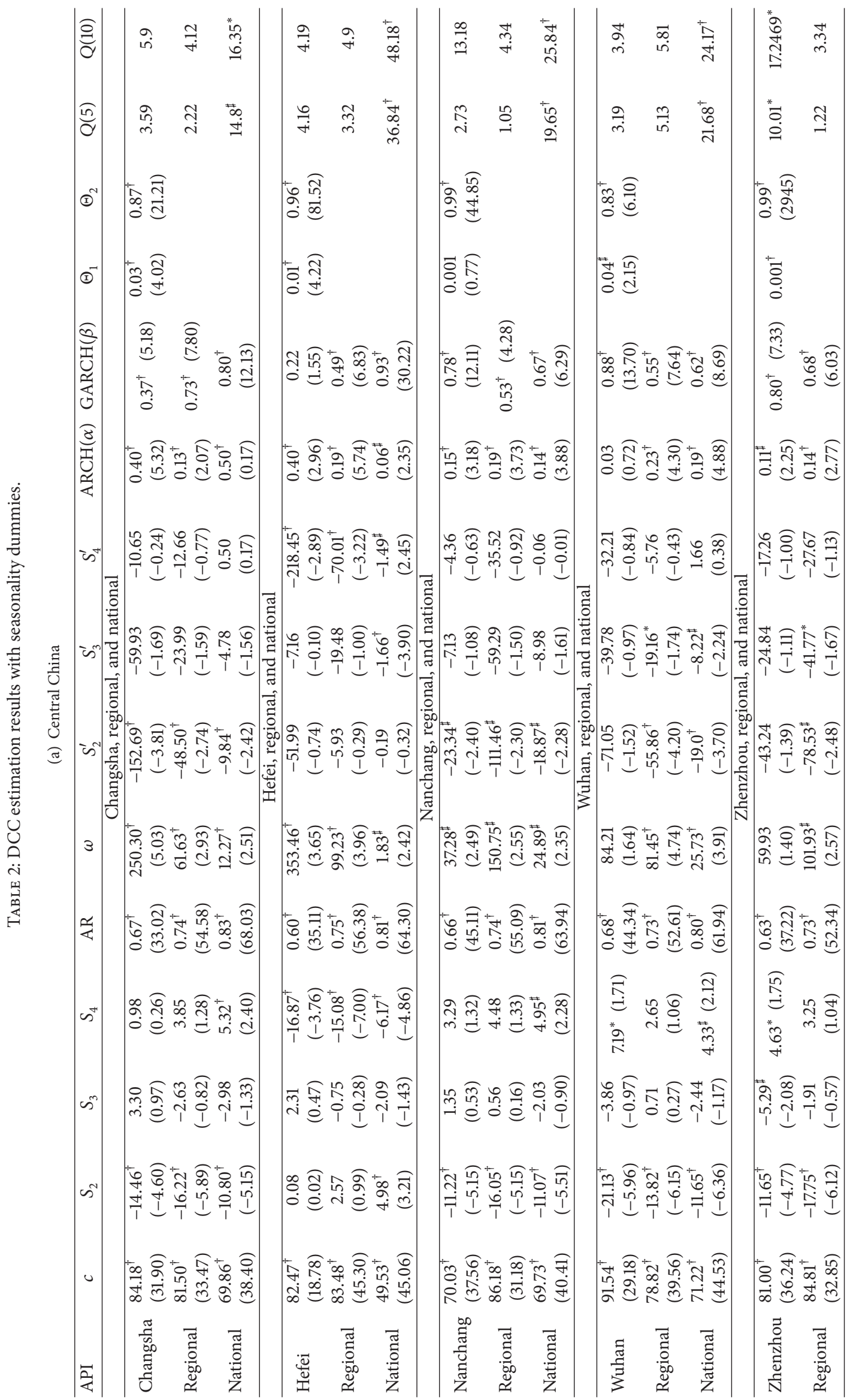




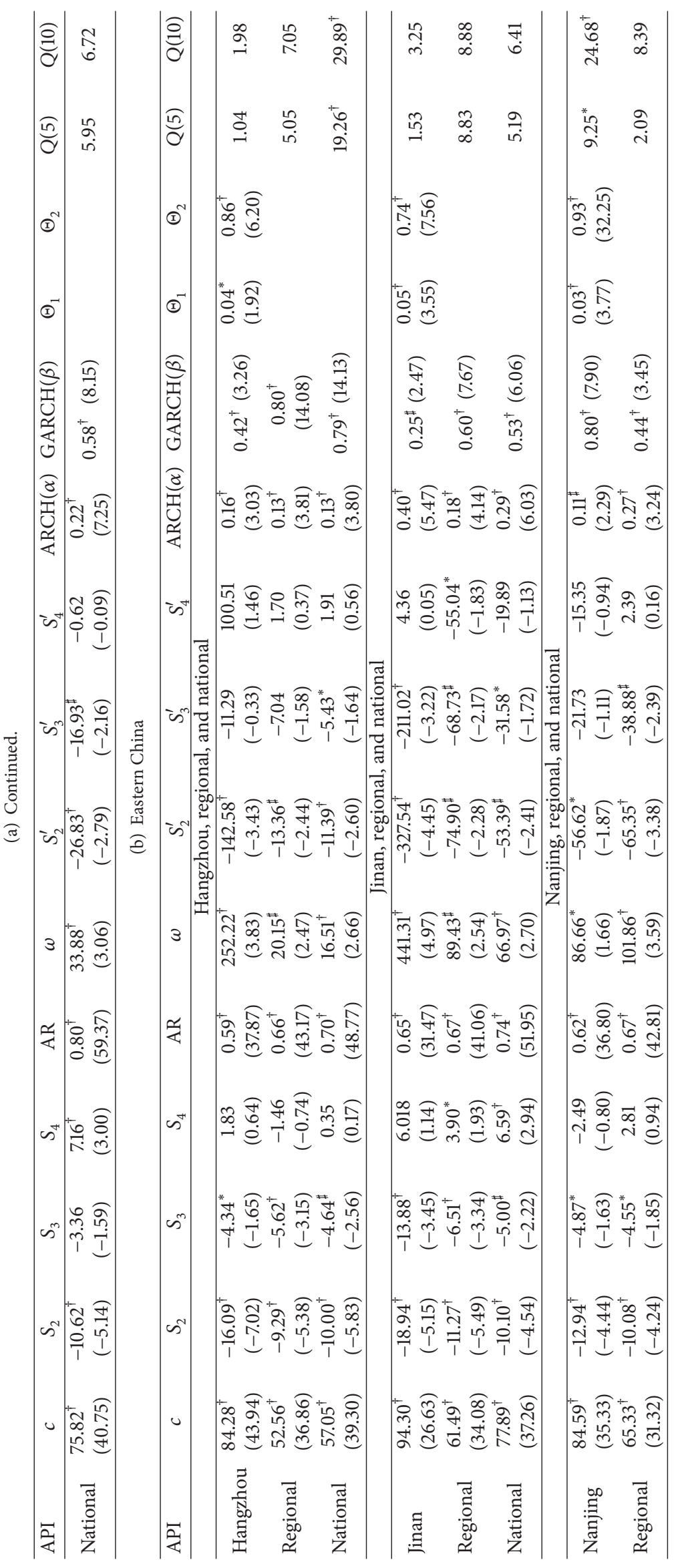




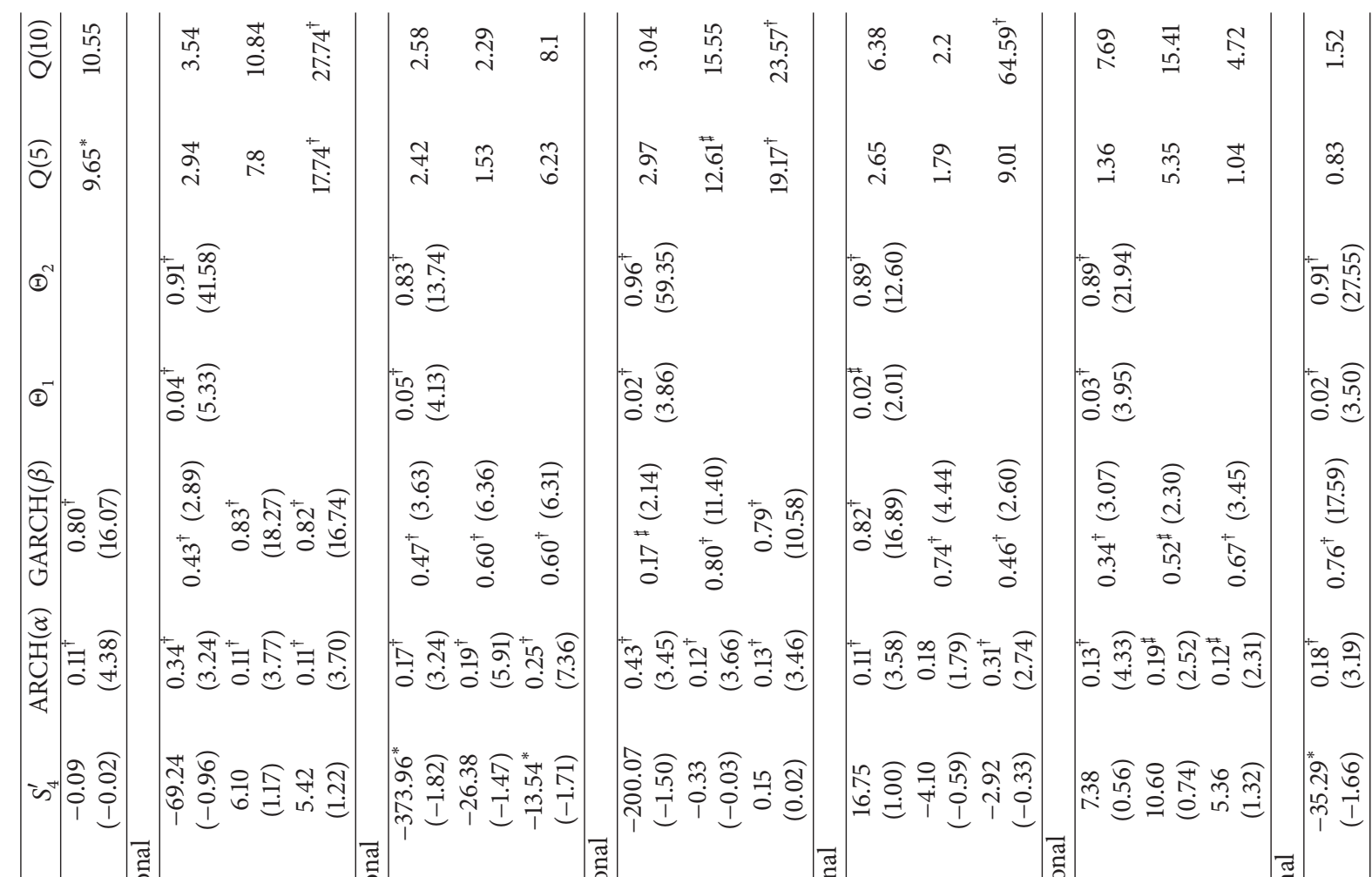

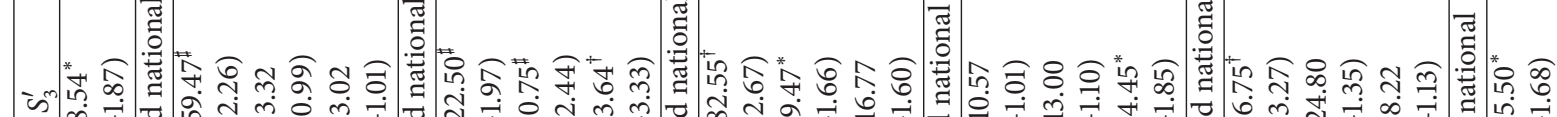

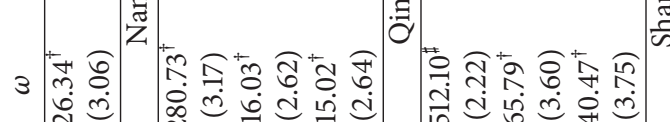

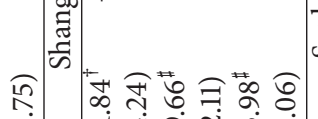

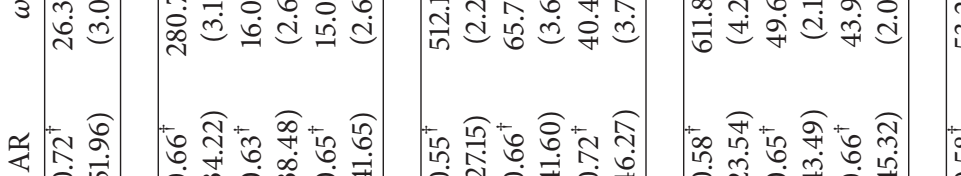

i

$\varangle$

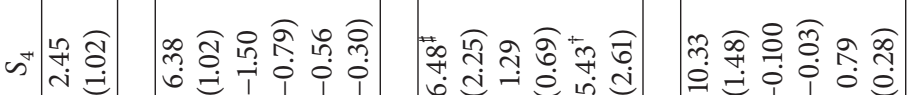

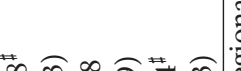

总

$\widehat{2}$

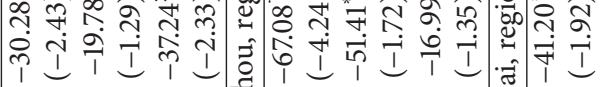

(

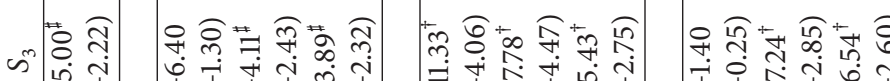

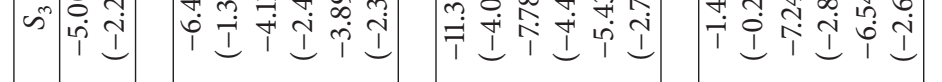

웅

in

in ${ }^{*}$

ส

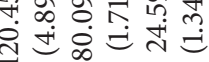

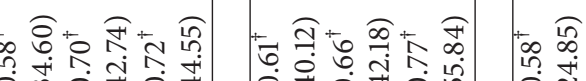

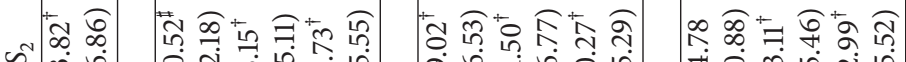

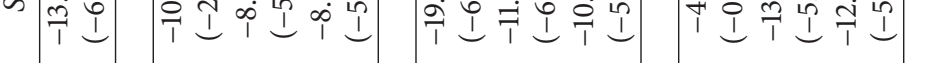

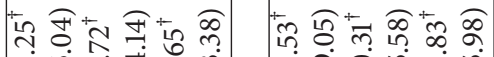

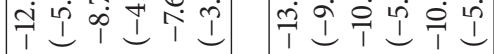

齐

u

कa

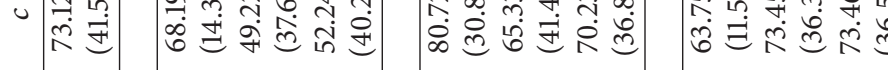

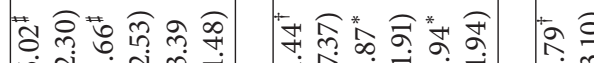

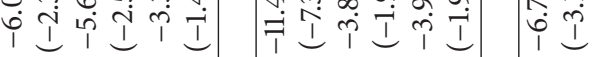

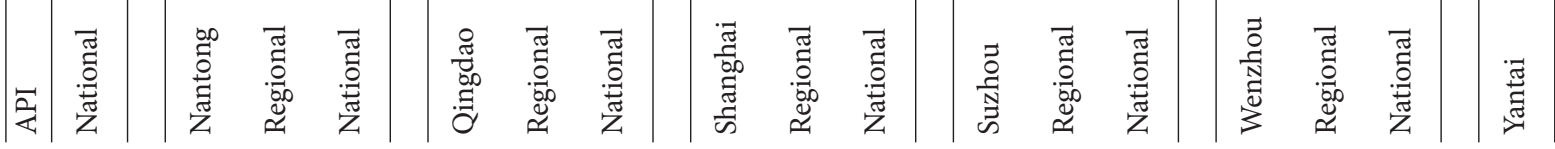




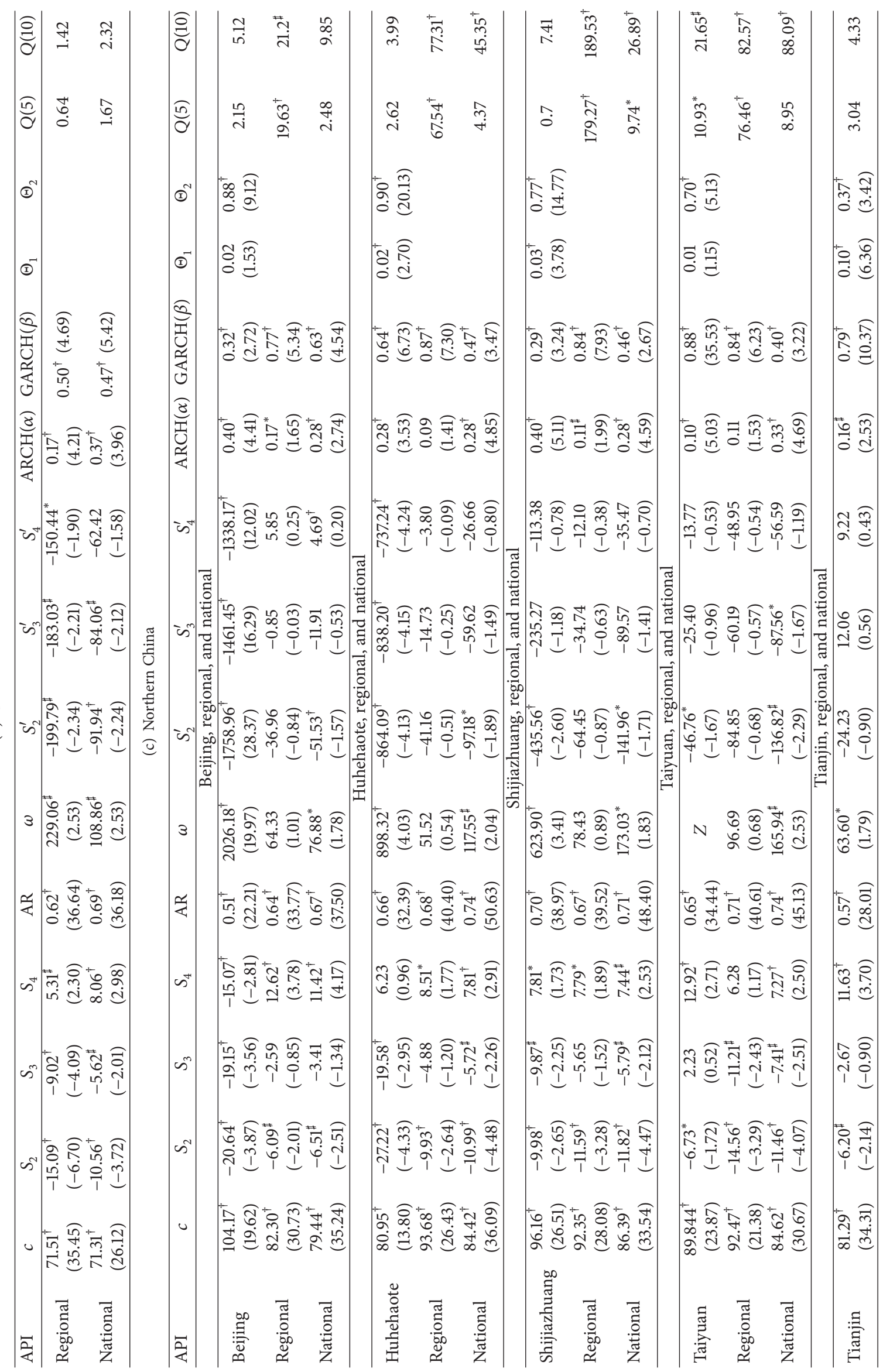




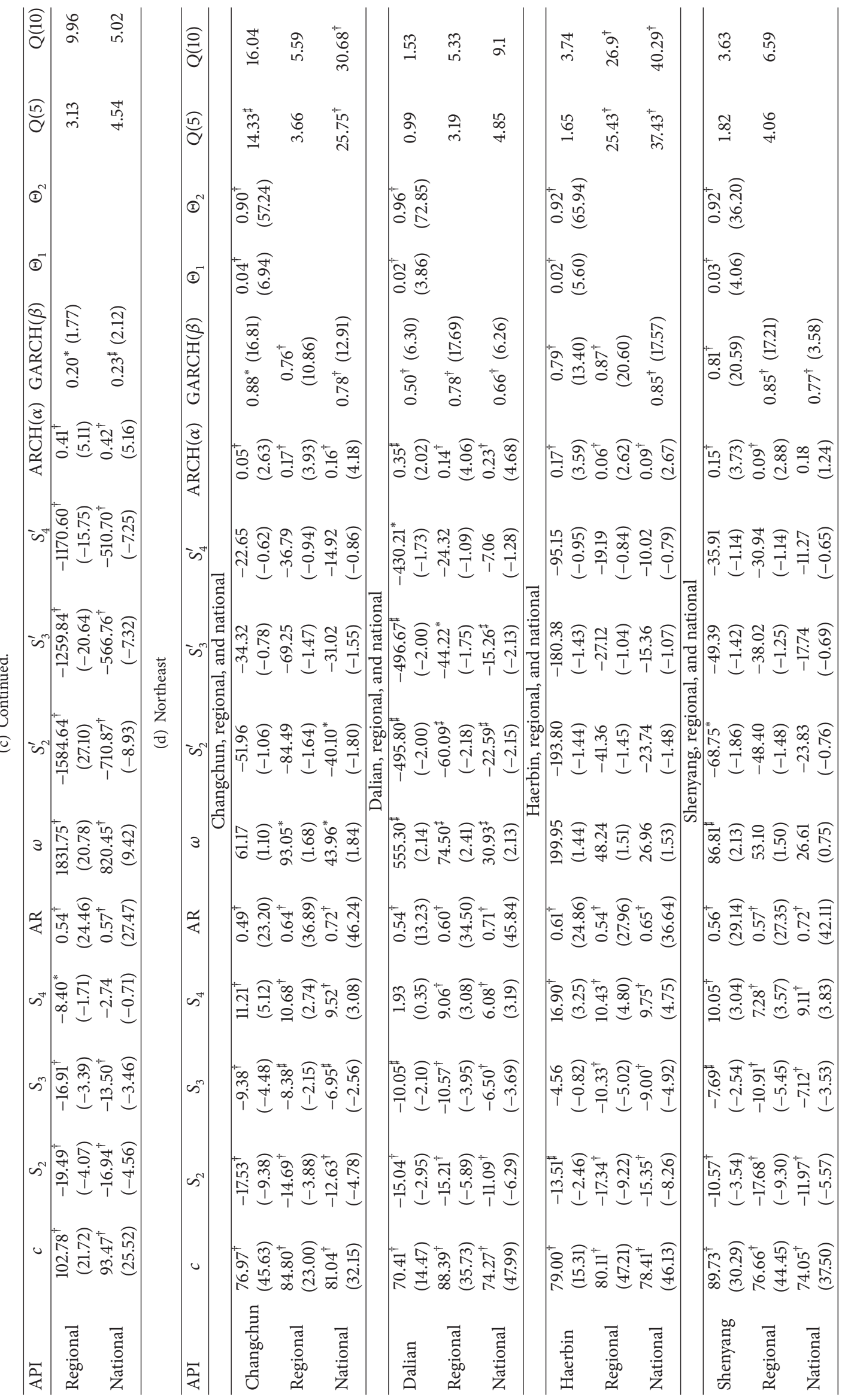




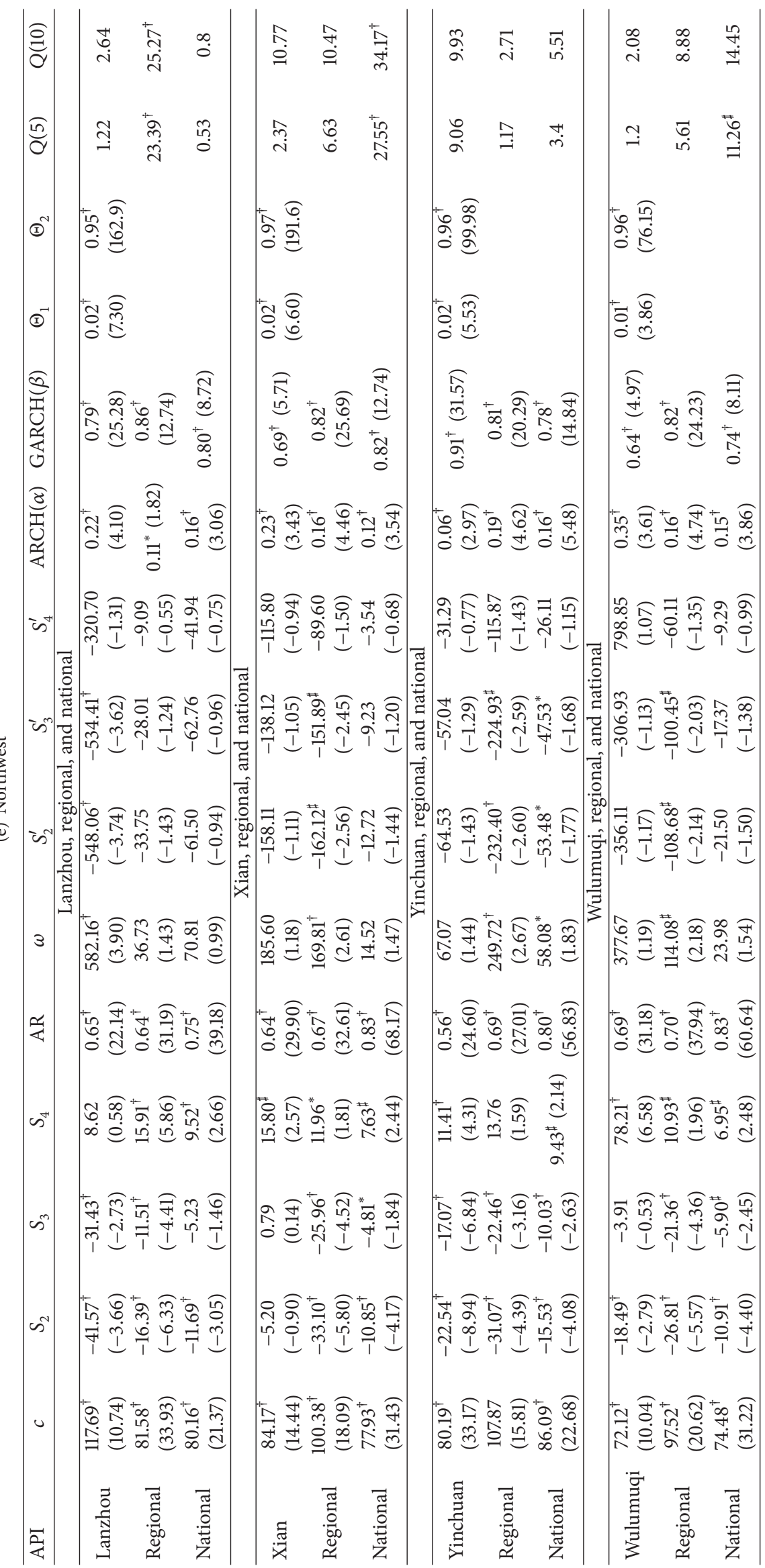




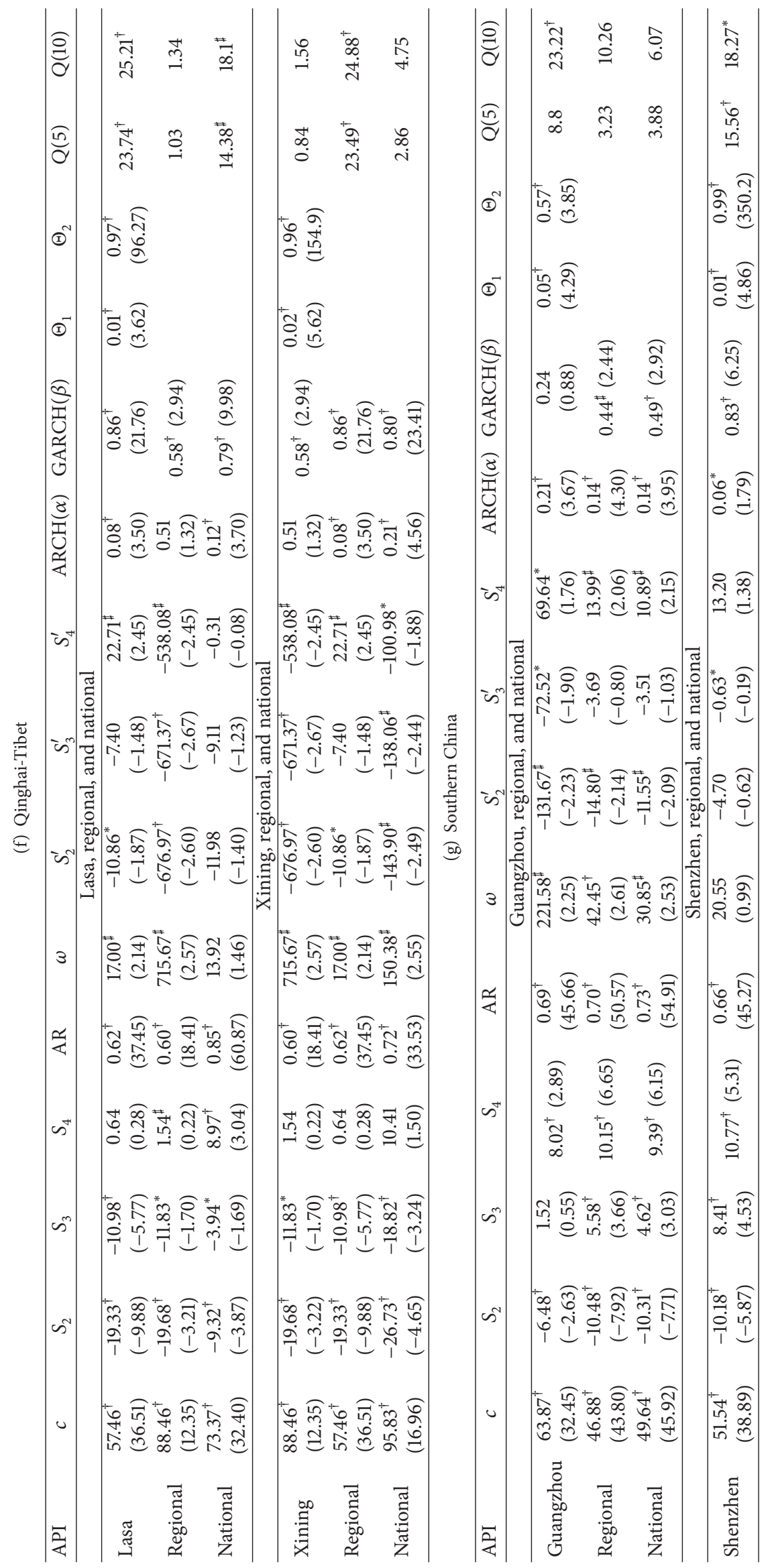




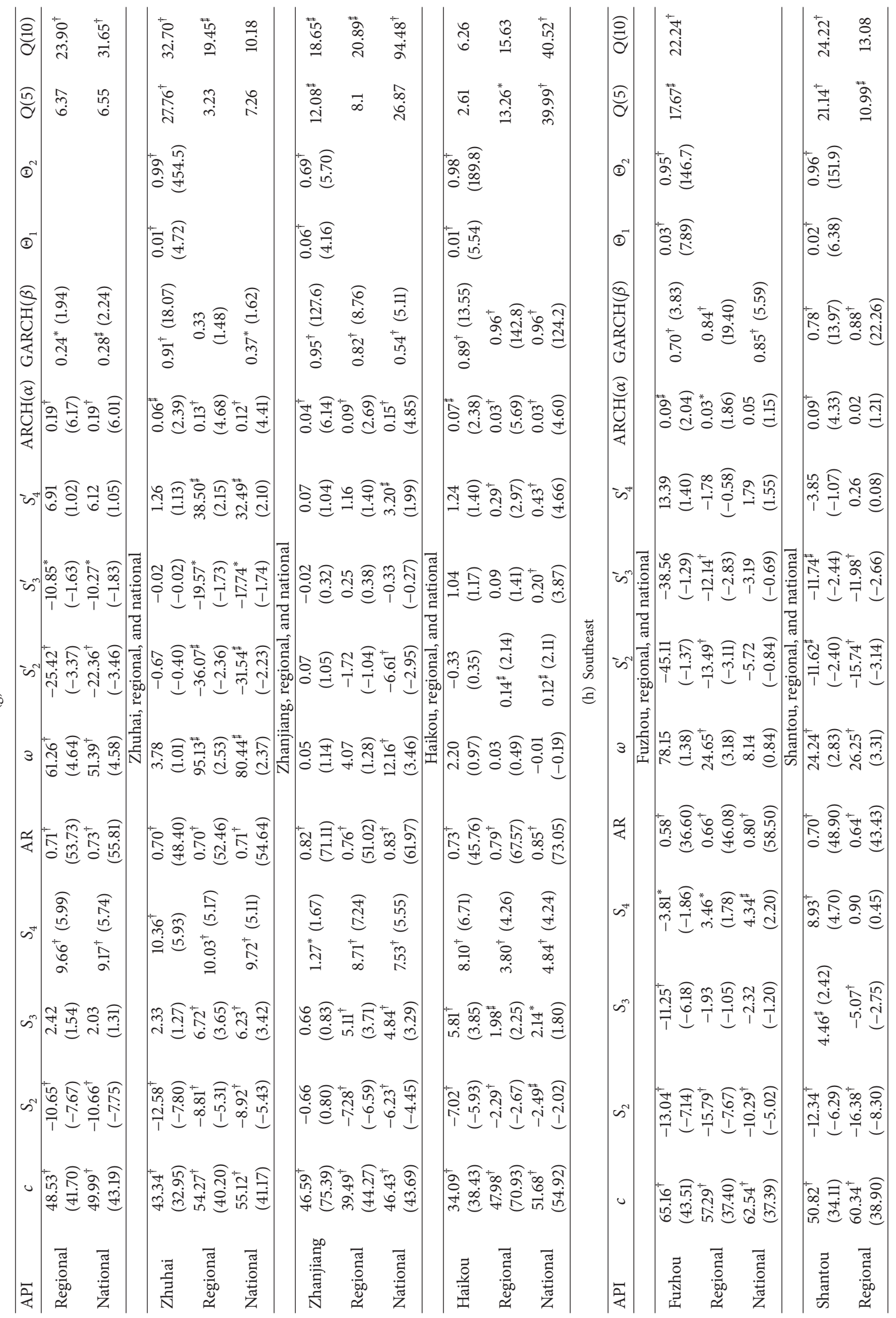




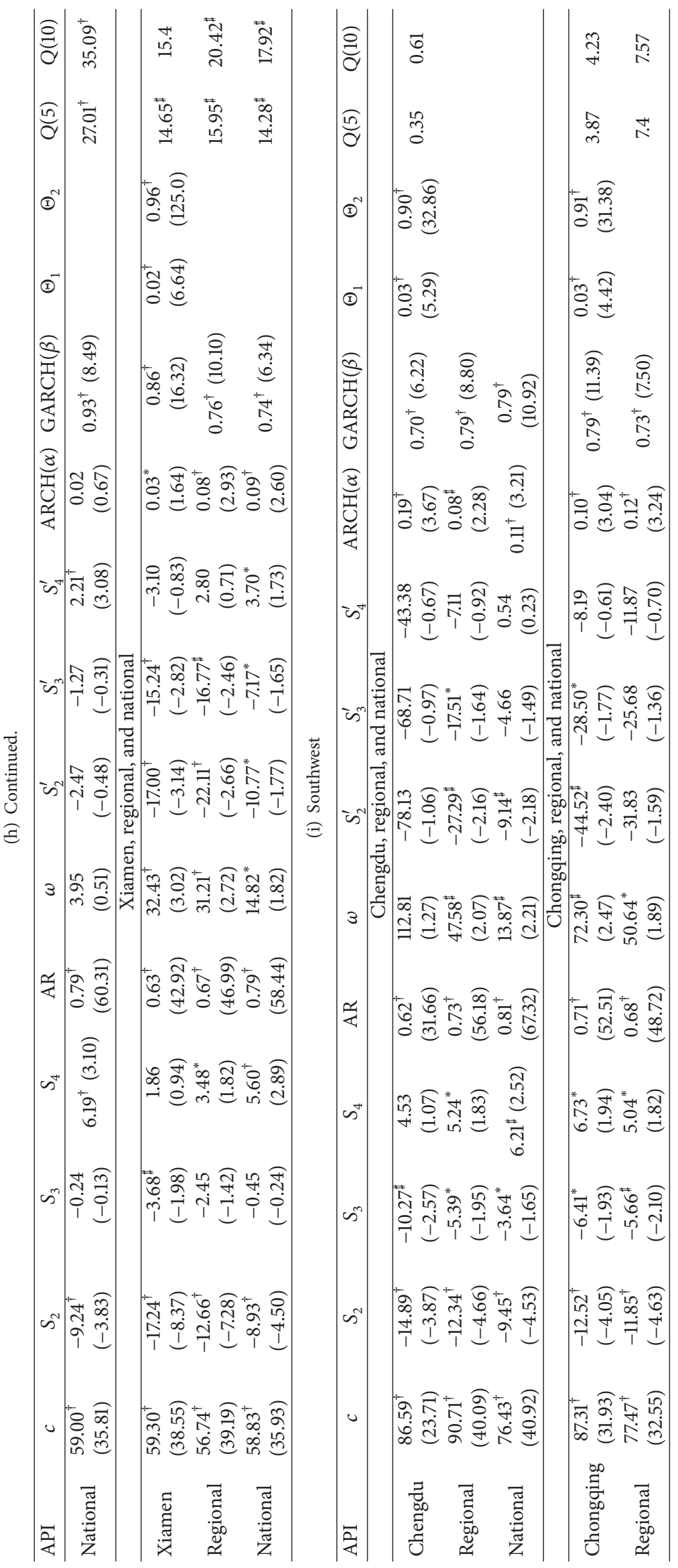




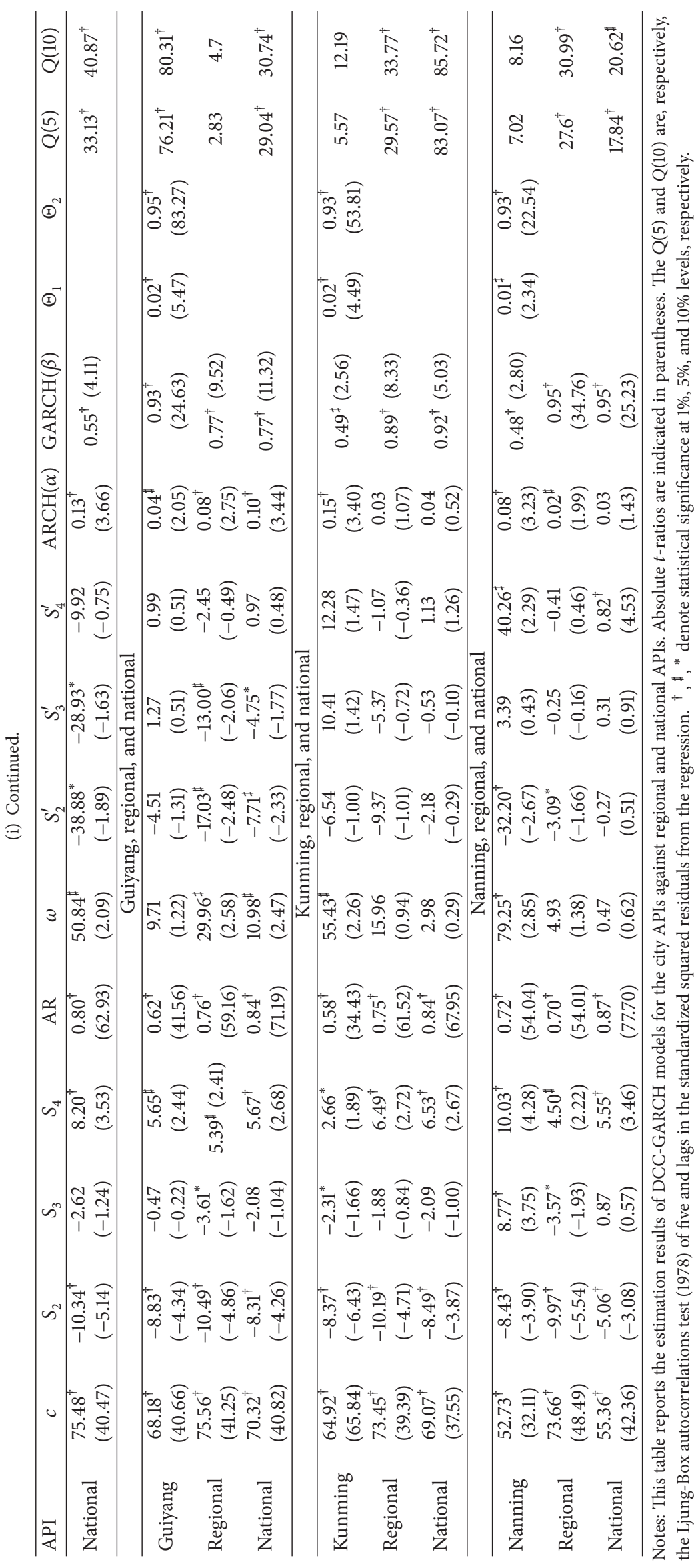



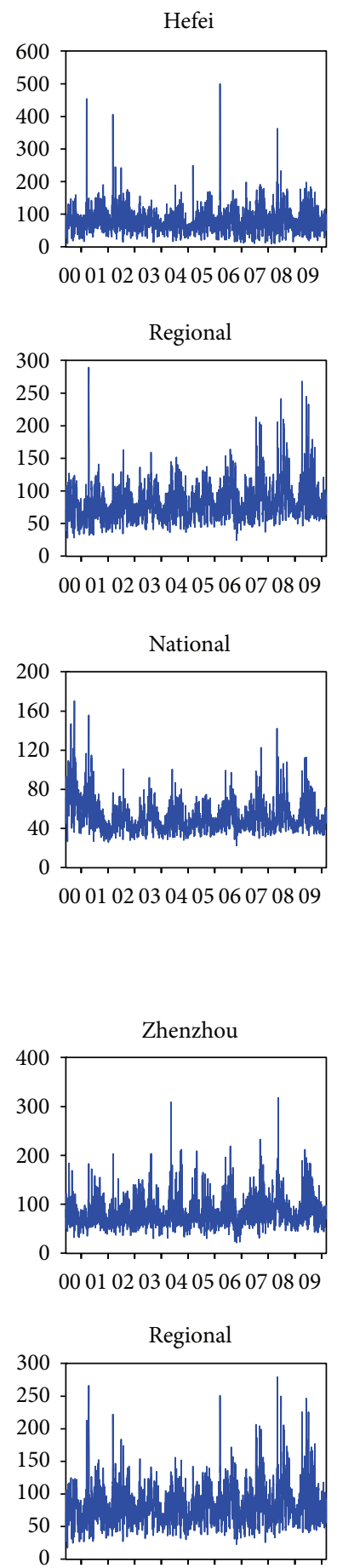

00010203040506070809

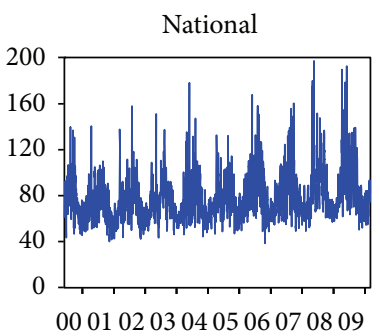

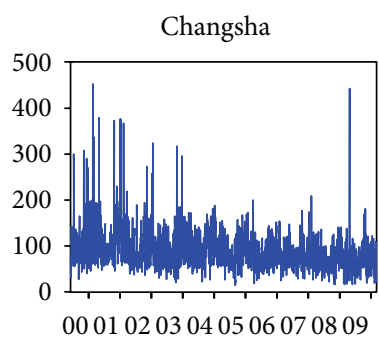
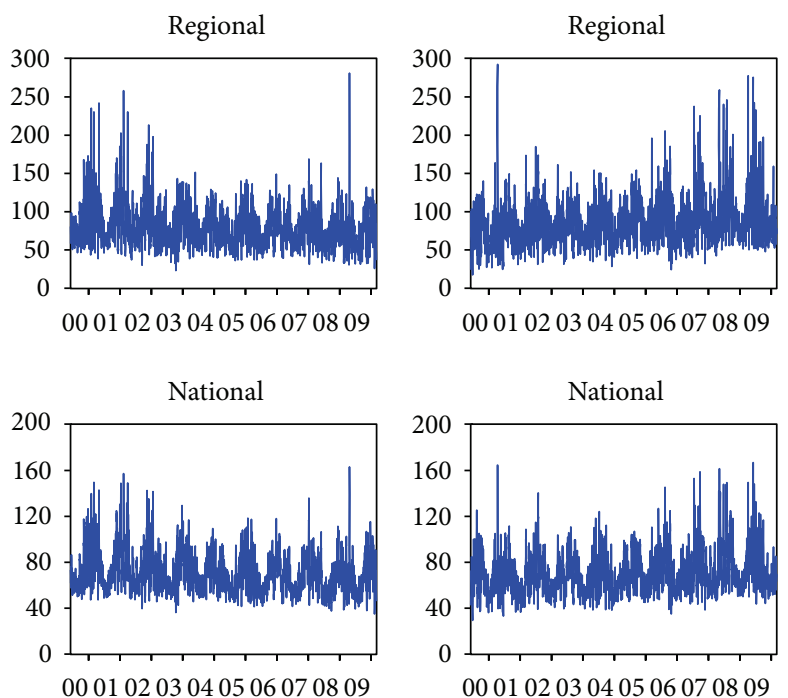

00010203040506070809
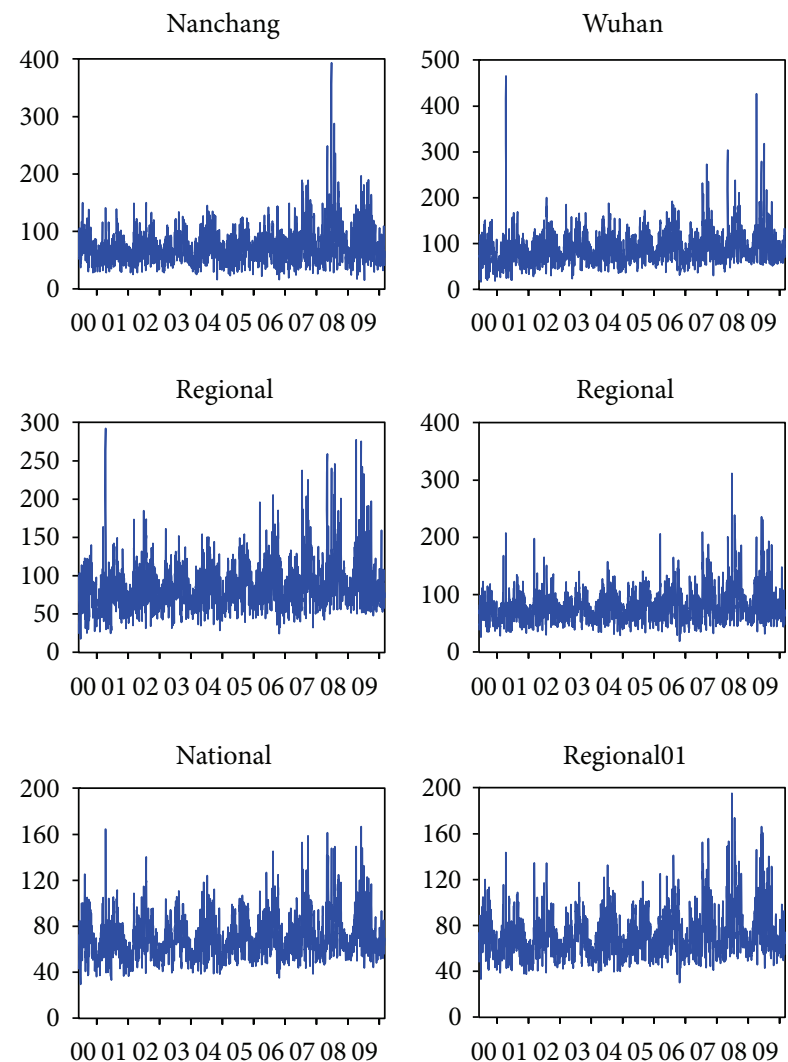
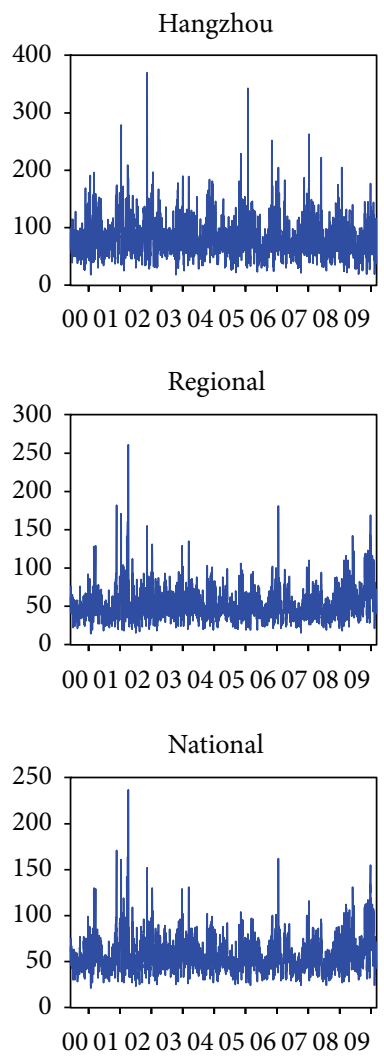
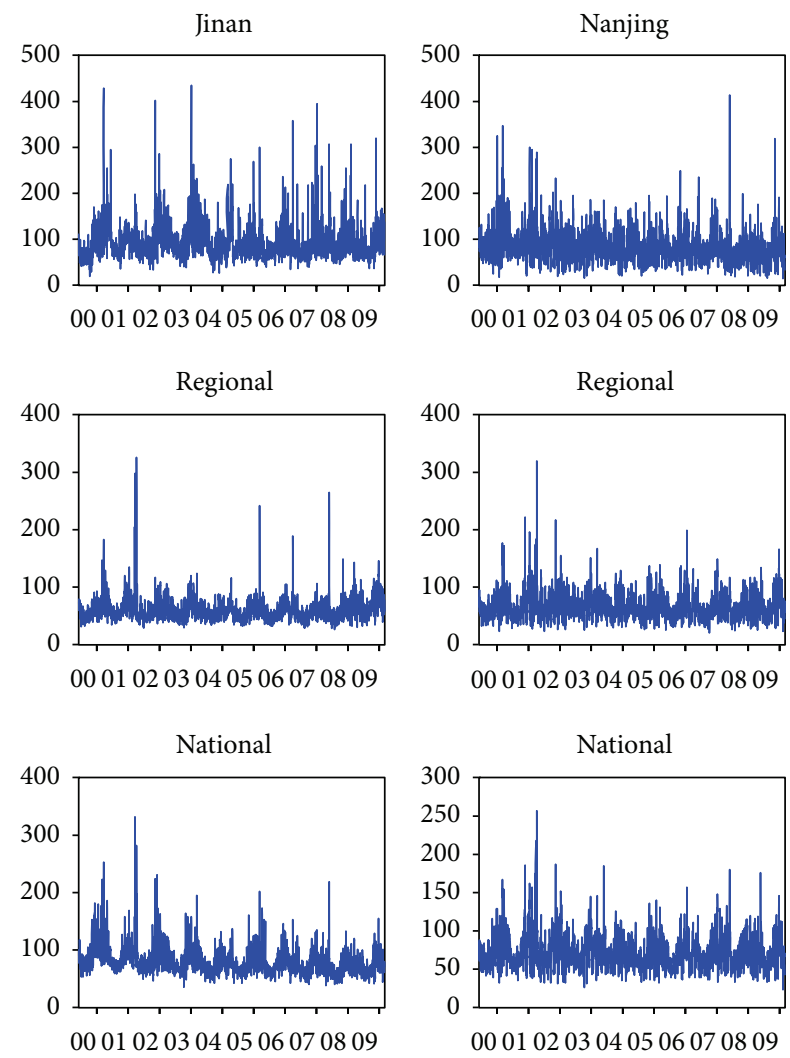

(a)

FIgure 1: Continued. 

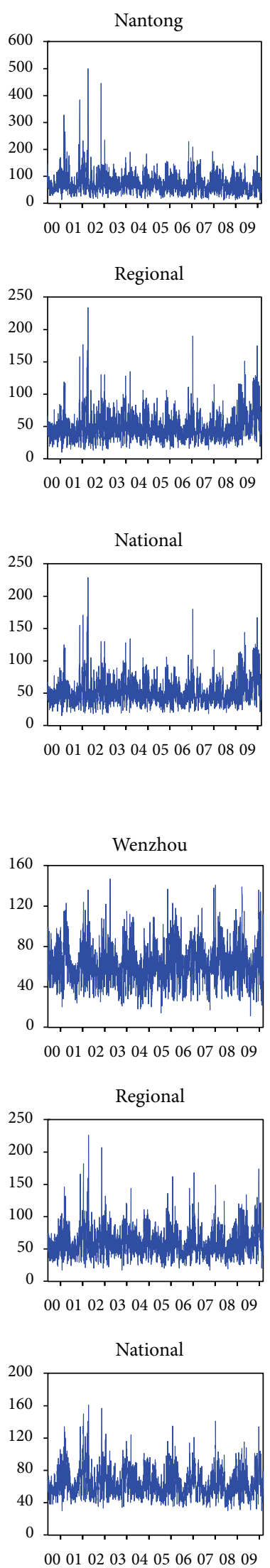
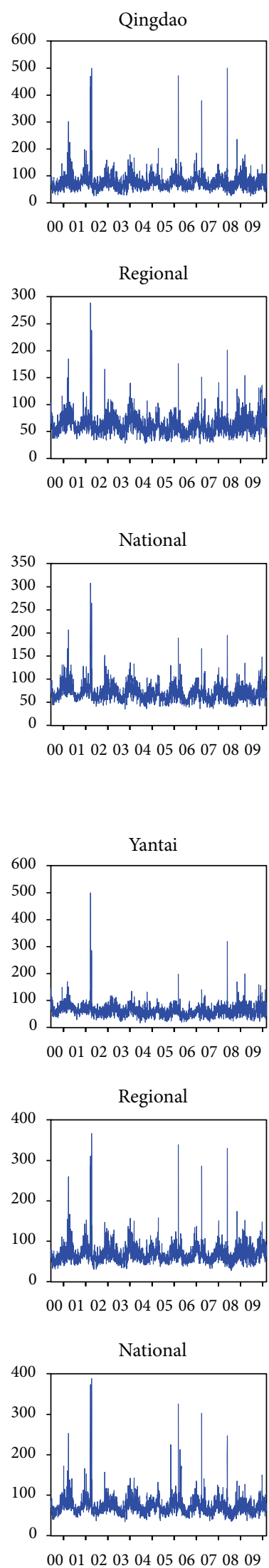
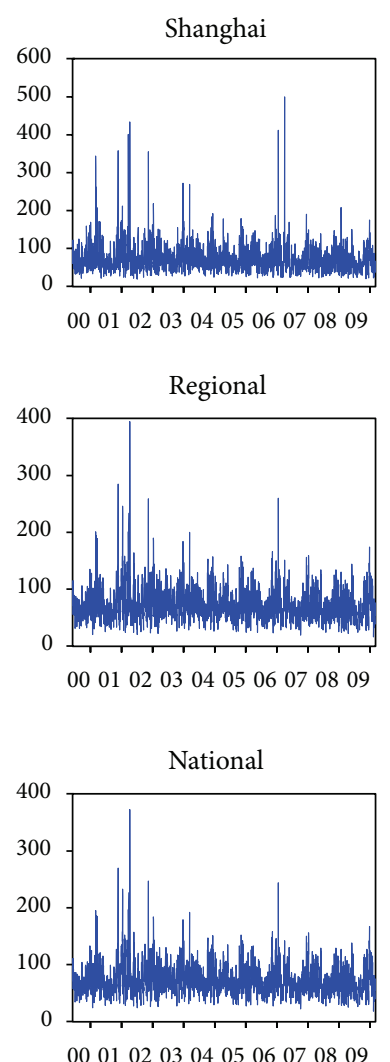
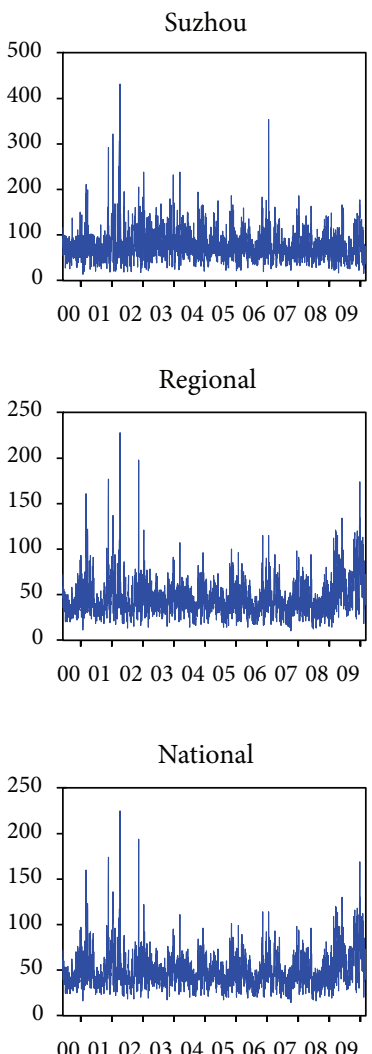

00010203040506070809
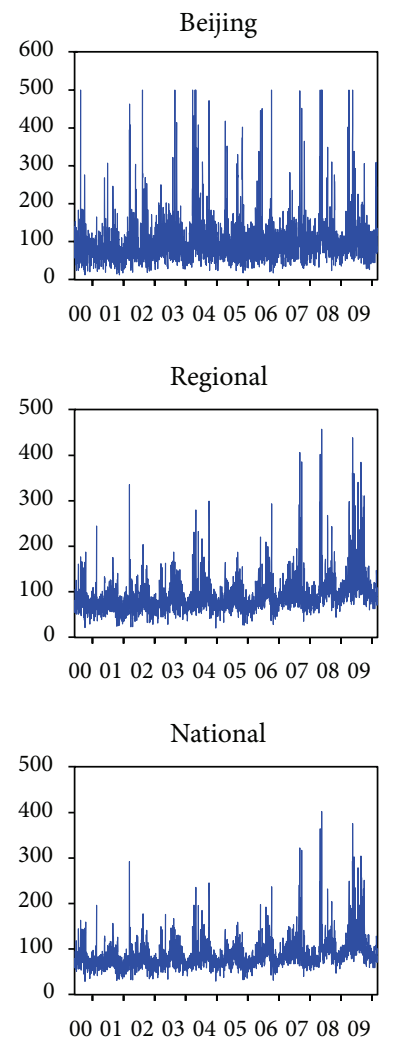

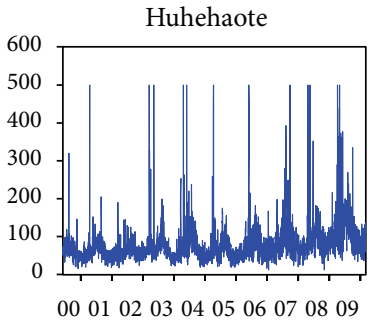

Regional

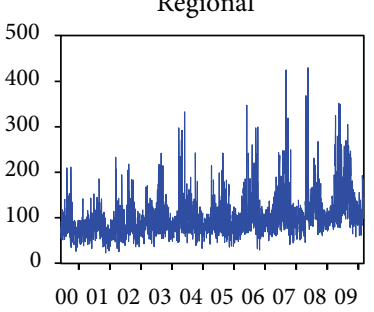

National

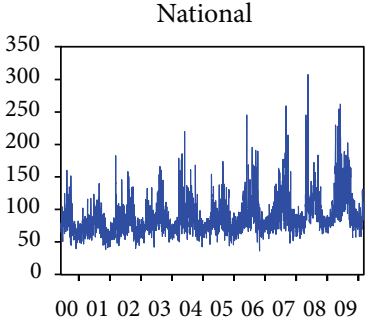

(b)

Figure 1: Continued. 

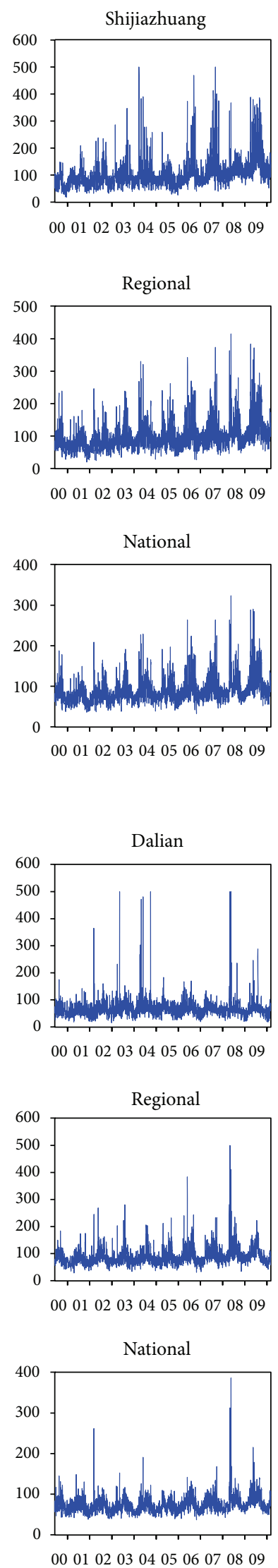
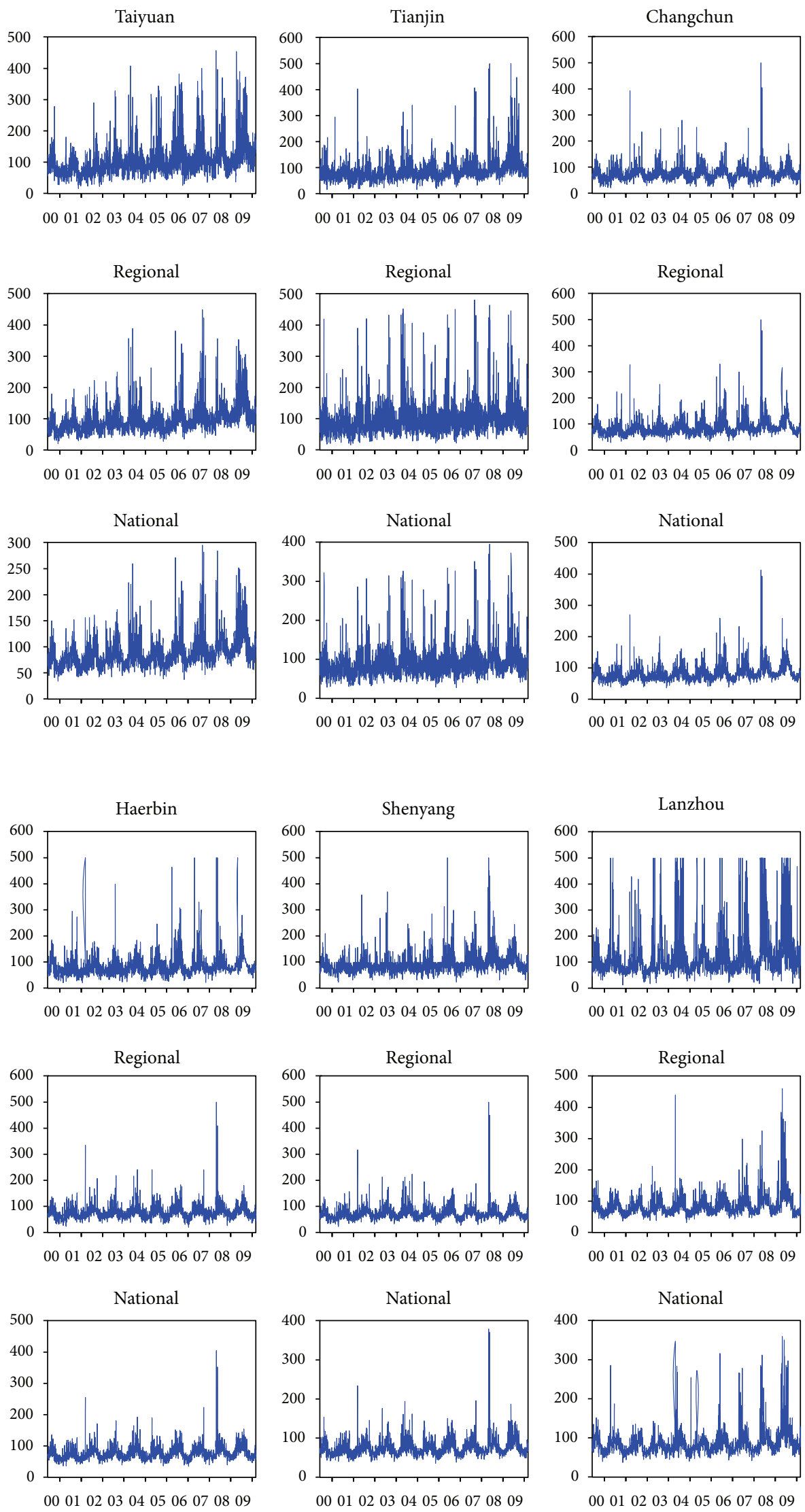

(c)

Figure 1: Continued. 

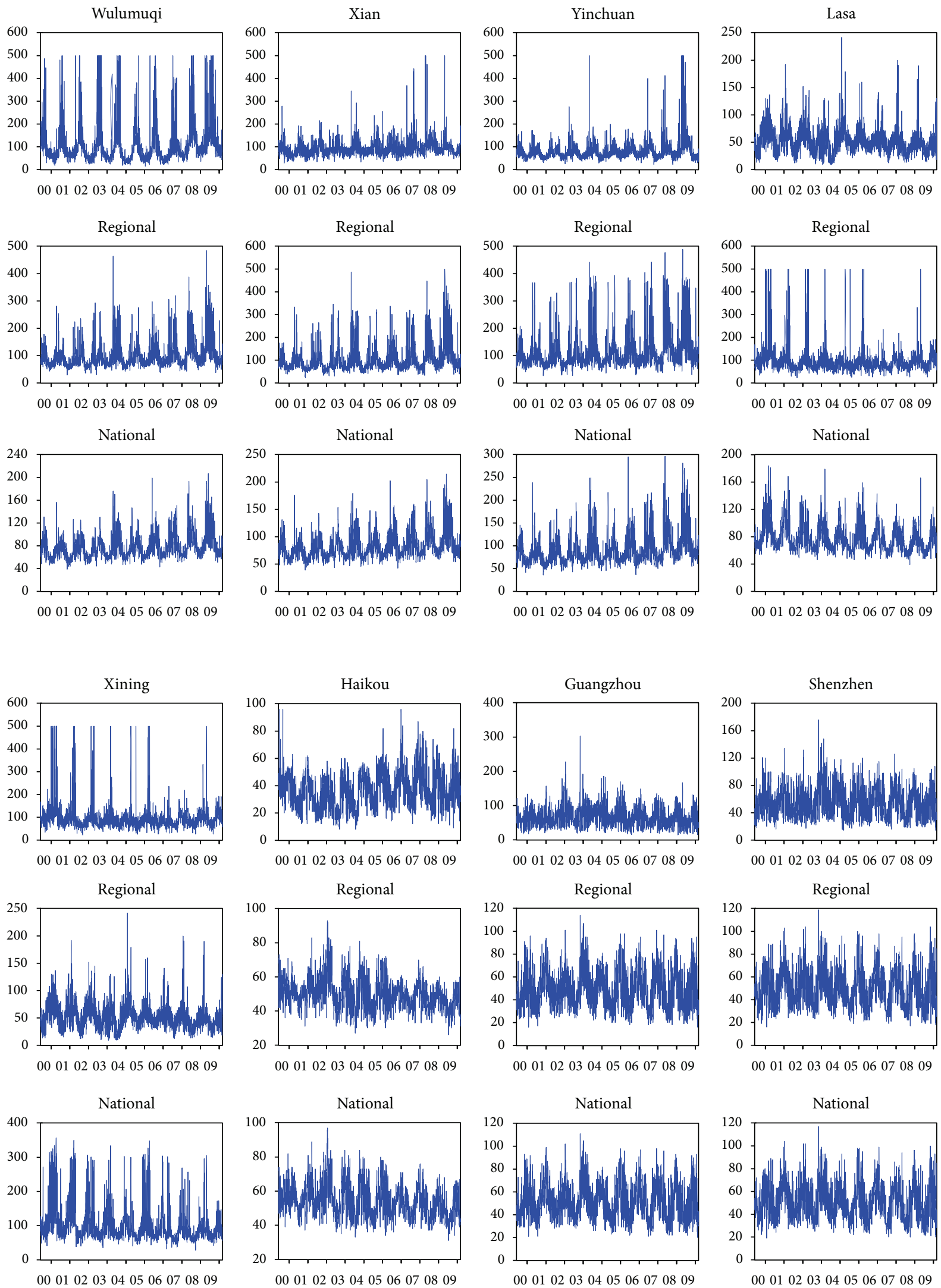

(d)

Figure 1: Continued. 

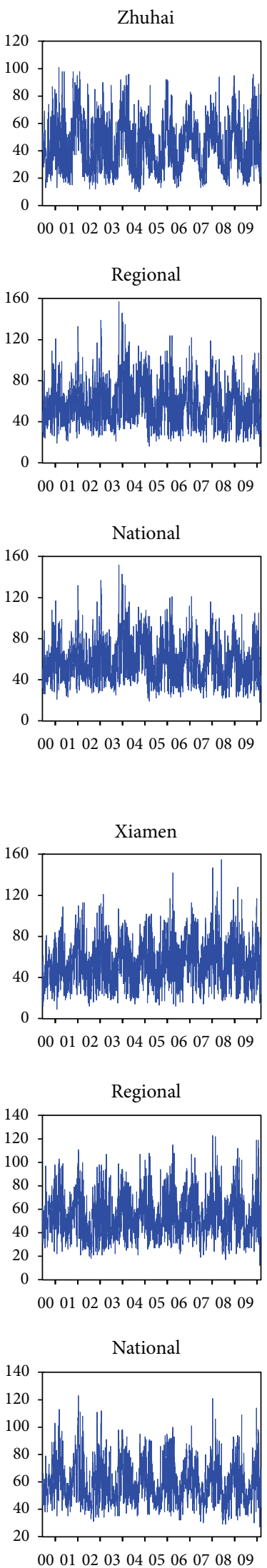
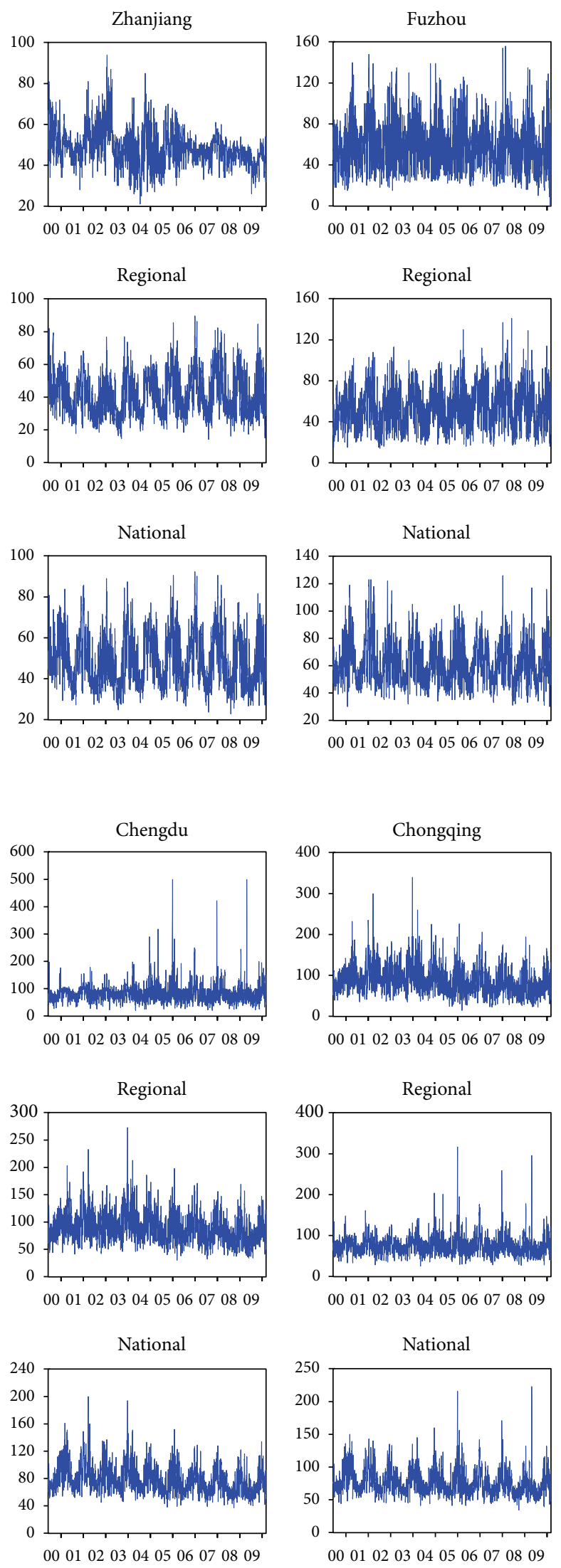

(e)
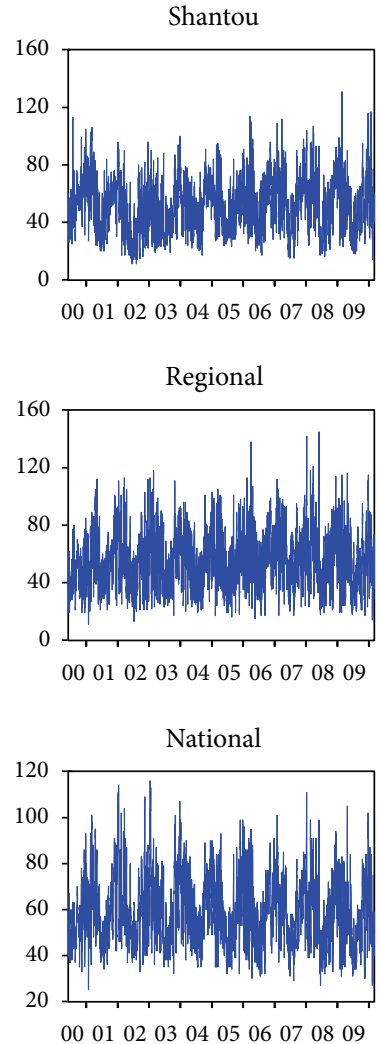

Guiyang
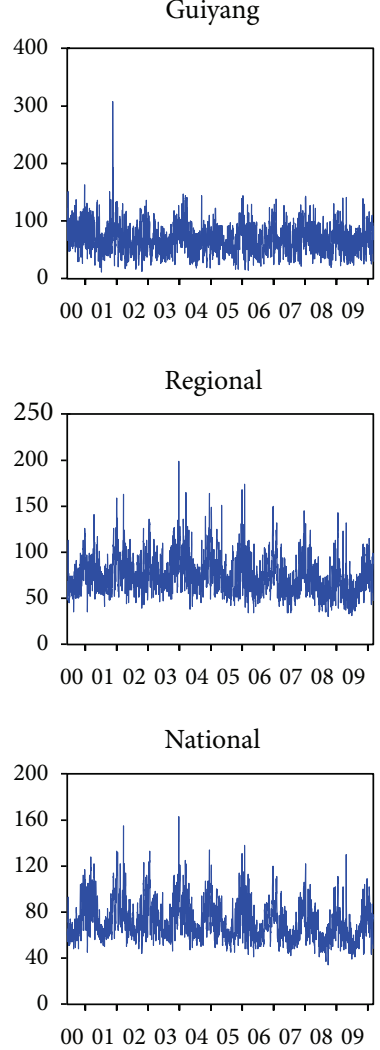

Figure 1: Continued. 

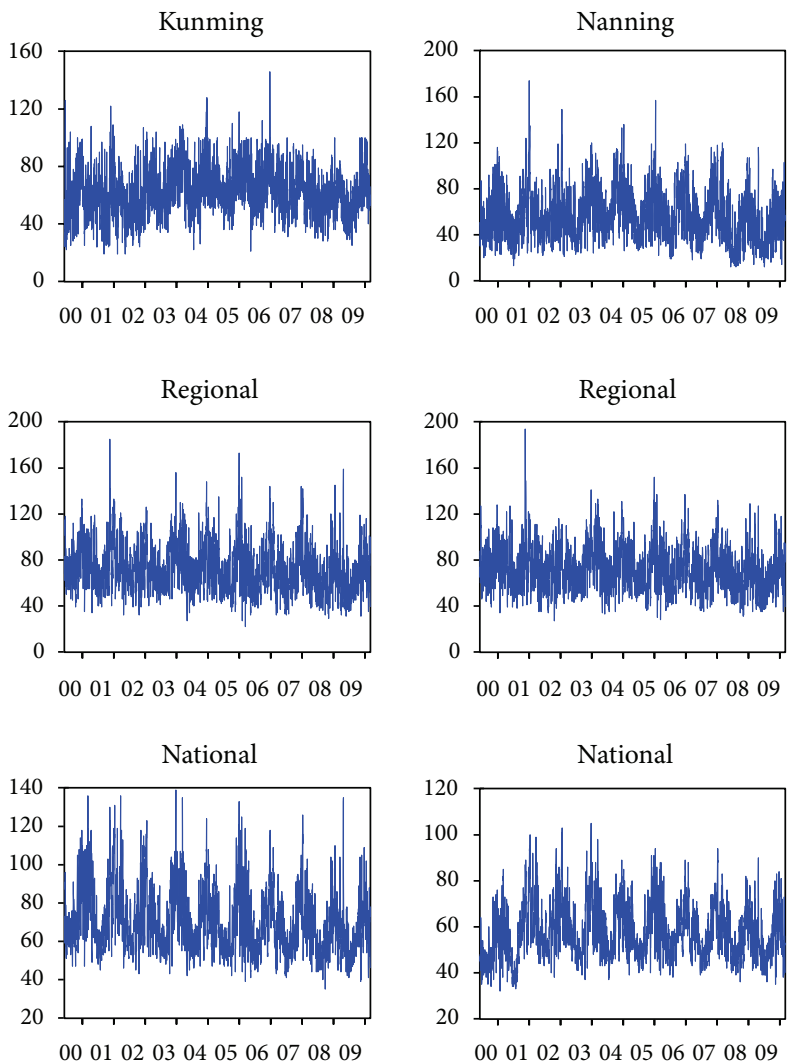

(f)

FIGURE 1: APIs for 42 sample cities and corresponding regional and national levels. 

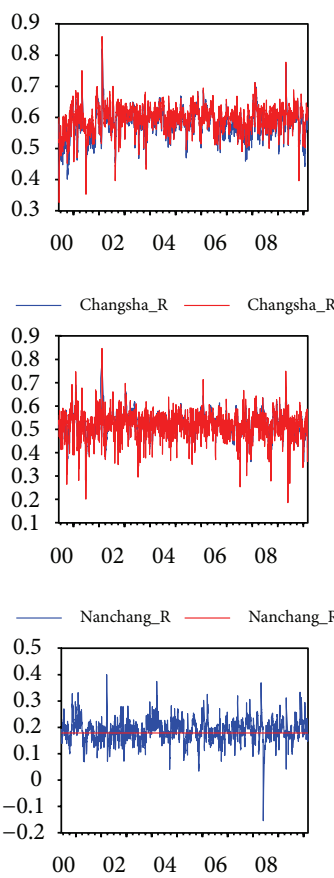

— Zhenzhou_R — Zhenzhou_RS
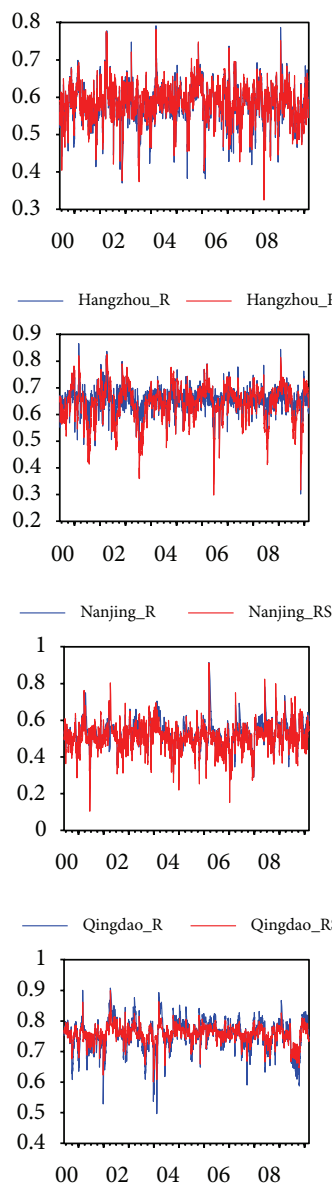

— Suzhou_R
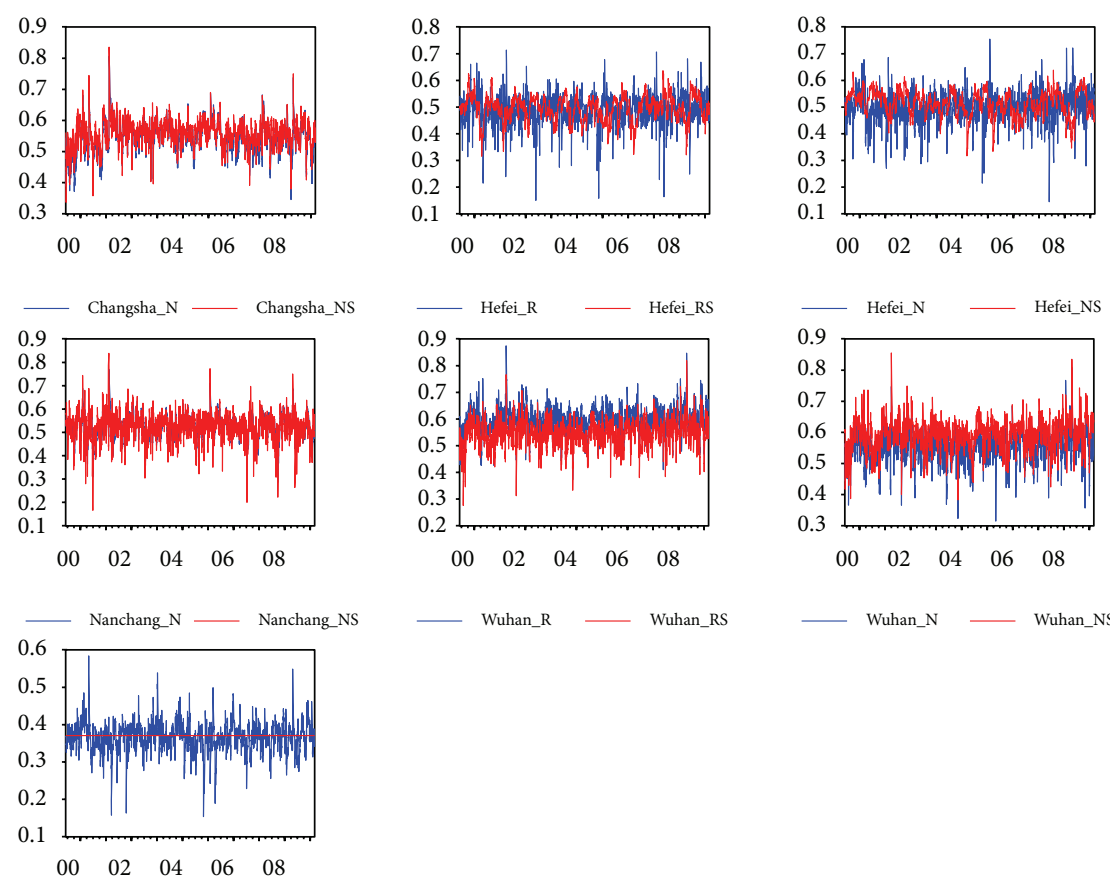

— Wuhan_R _ Wuhan_RS — Wuhan_N _ Wuhan_NS
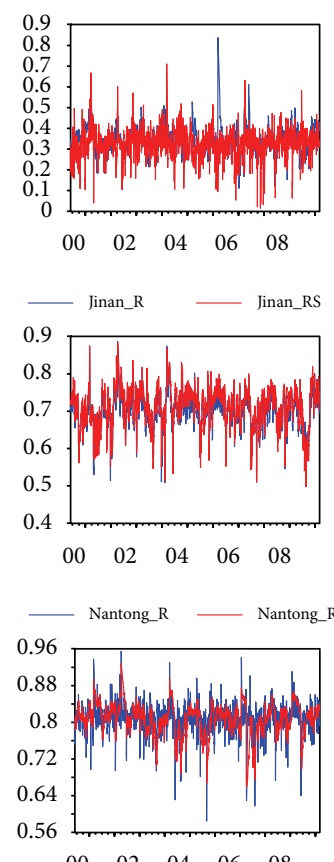

_ Shanghai_R _ Shanghai RS

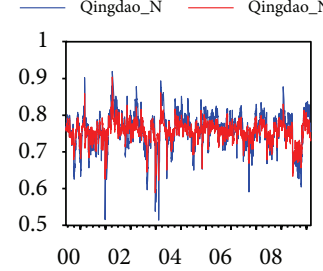

— Suzhou_N
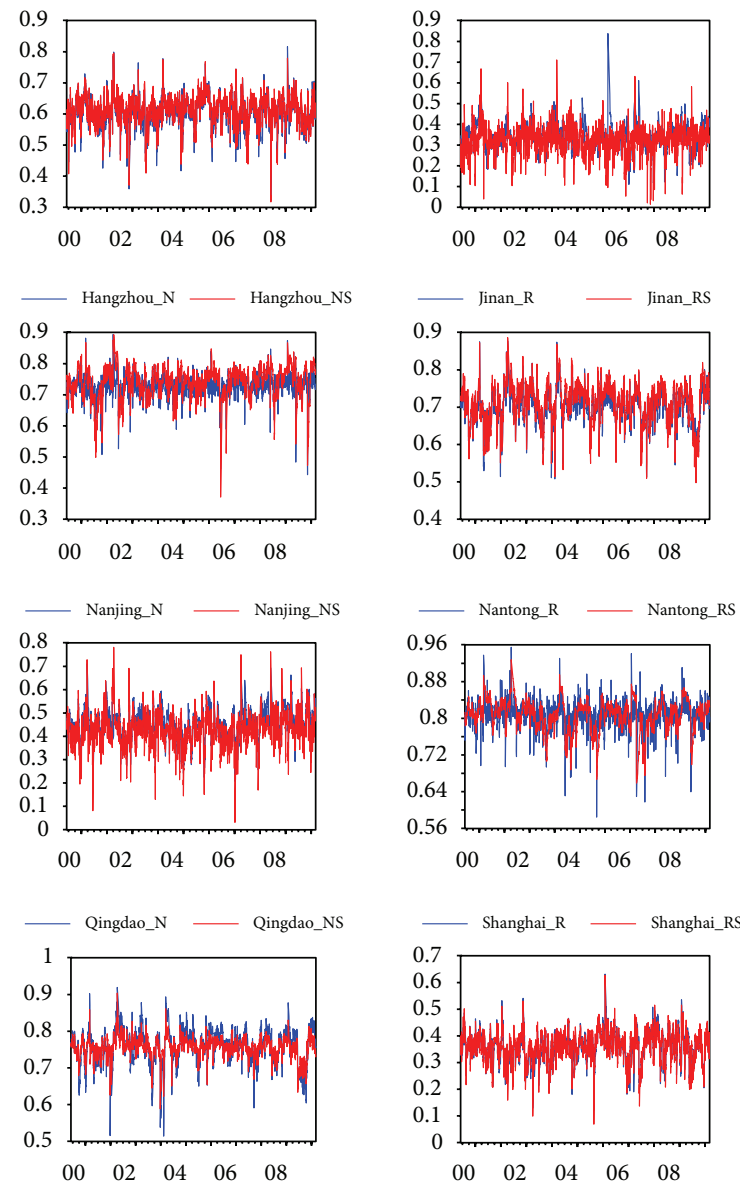

— Wenzhou_R — Wenzhou_RS
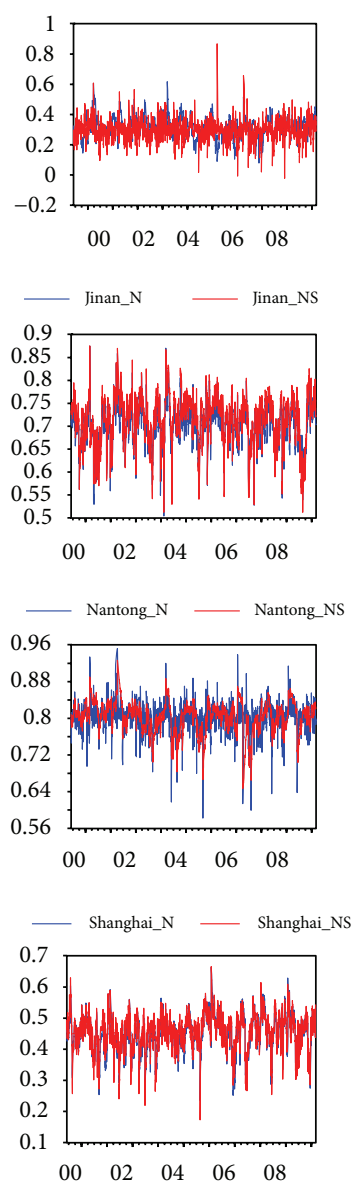

— Wenzhou_N _ Wenzhou_NS

(a)

Figure 2: Continued. 

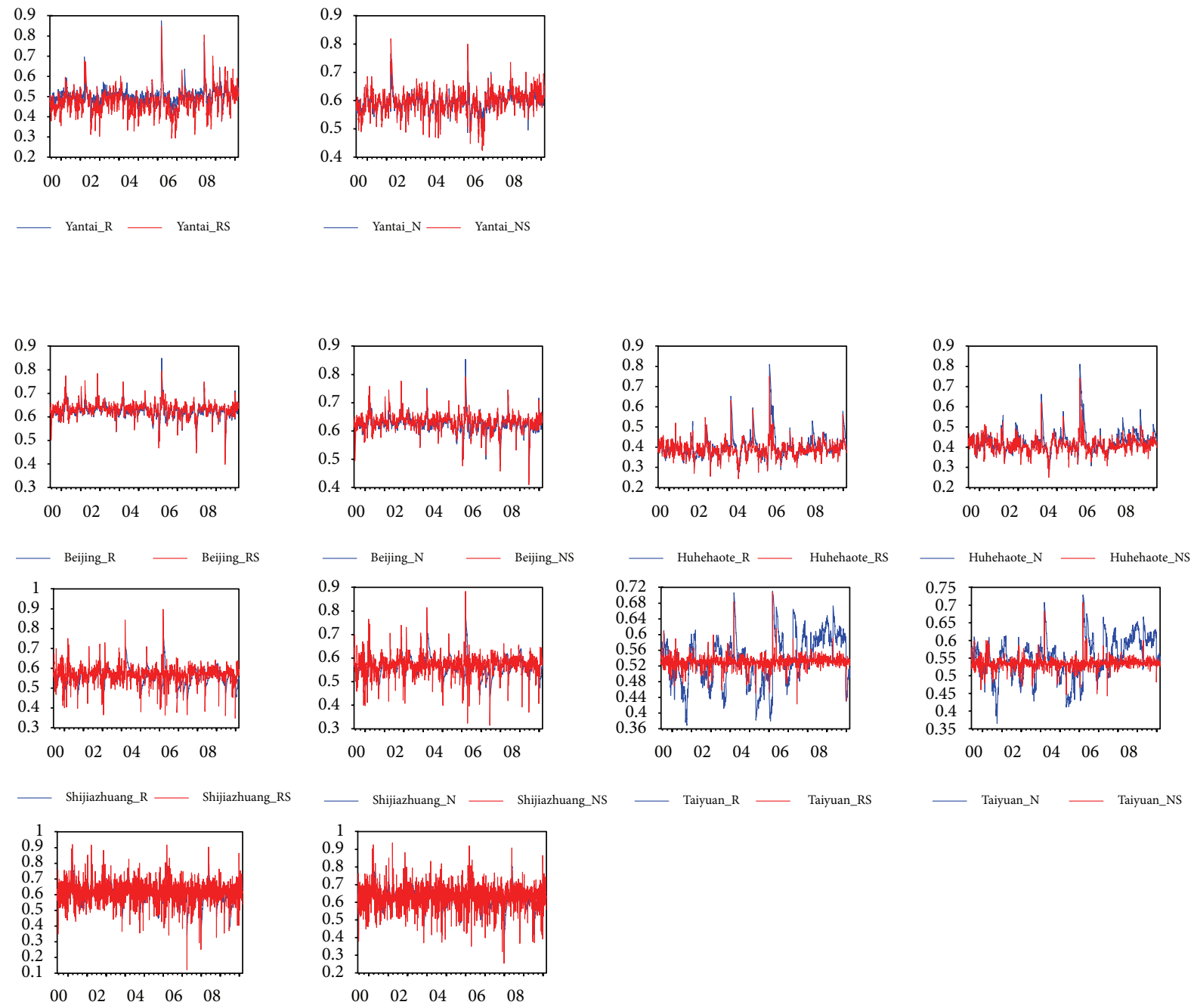

- Tianjin_R $\quad$ - Tianjin_RS
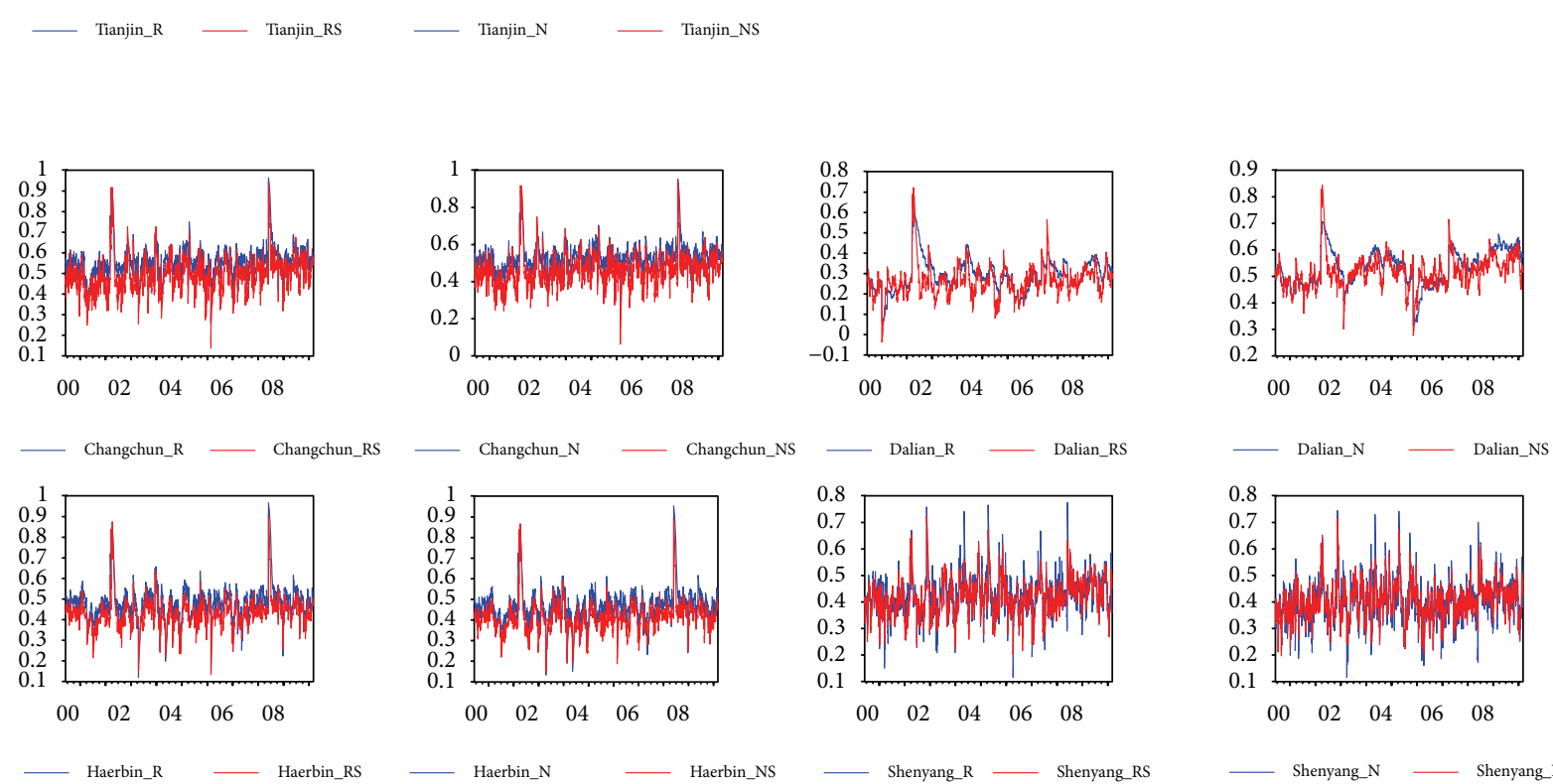

$\longrightarrow$ Haerbin_N $\quad$ Haerbin_NS

b)

FIGURE 2: Continued. 


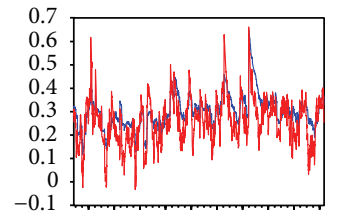

$\begin{array}{lllll}00 & 02 & 04 & 06 & 08\end{array}$
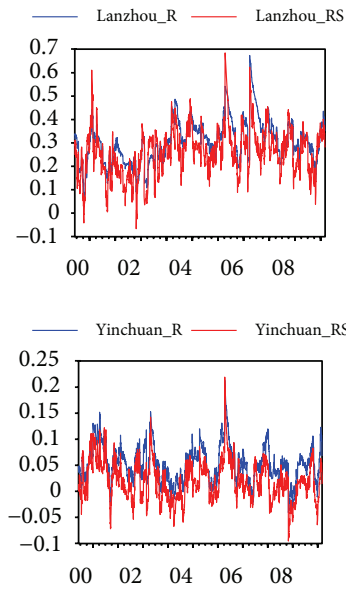

Lasa_R $\quad$ Lasa_RS
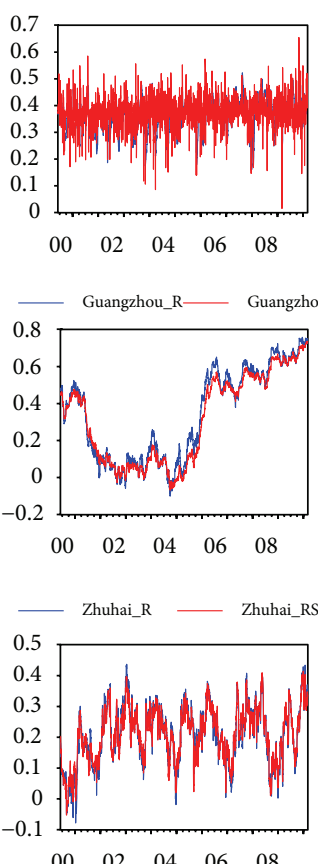

$\begin{array}{lllll}00 & 02 & 04 & 06 & 08\end{array}$

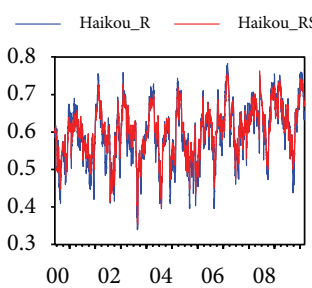

_ Shantou_R _ Shantou_RS

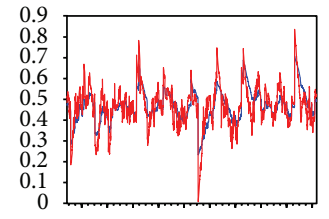

$\begin{array}{lllll}00 & 02 & 04 & 06 & 08\end{array}$
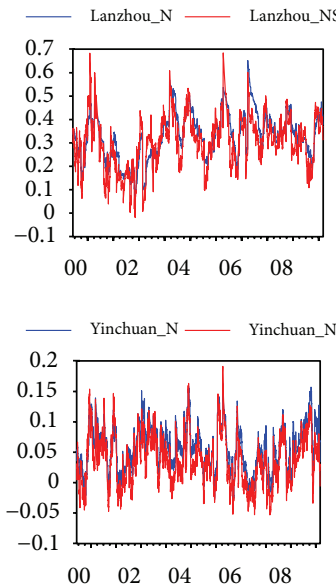

Lasa_N $\quad$ Lasa_NS
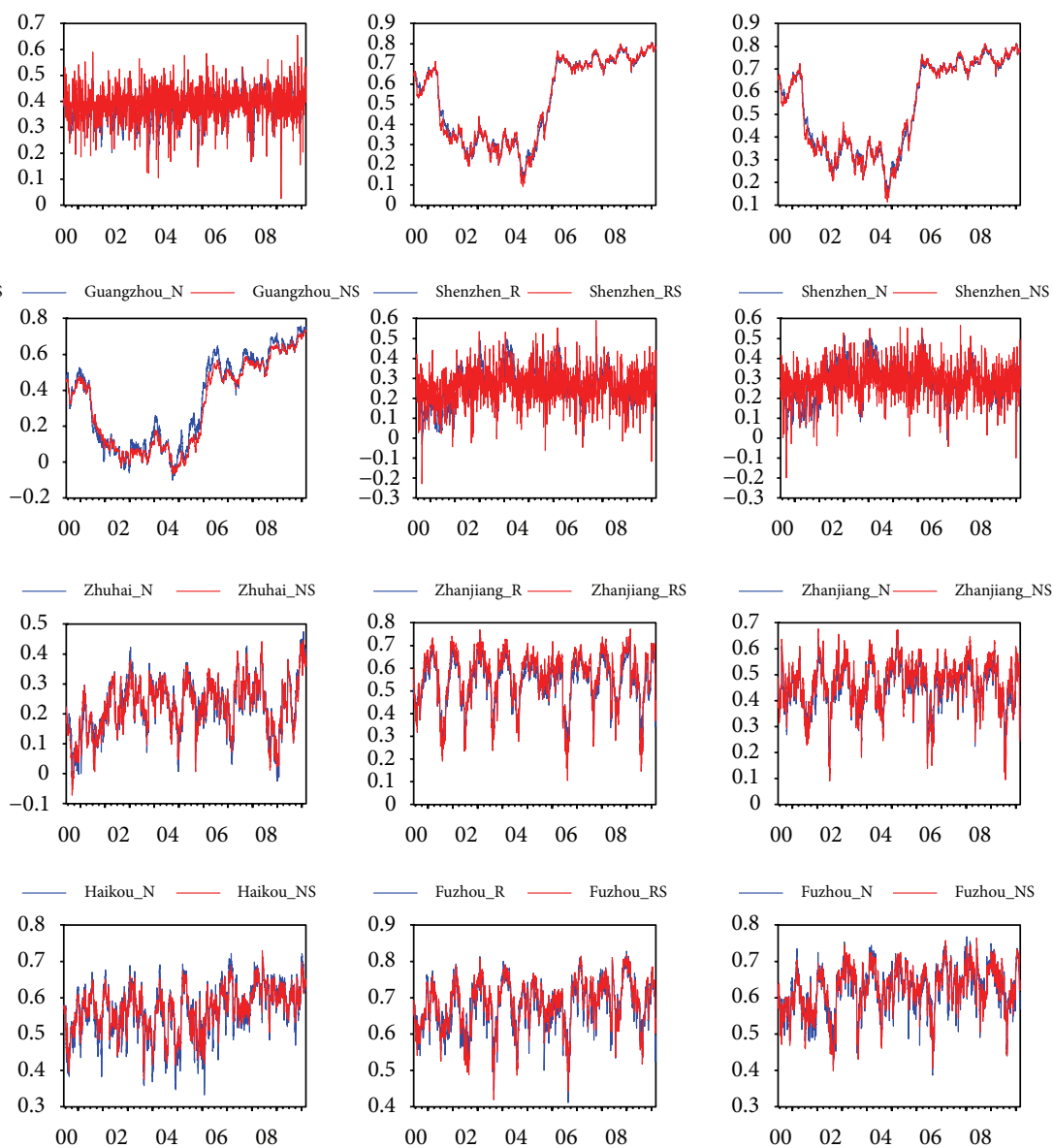

(c)
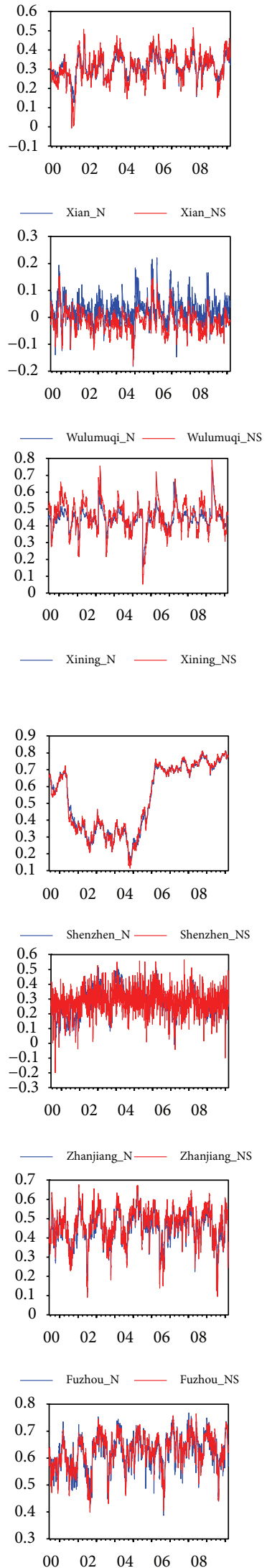

$\begin{array}{lllll}00 & 02 & 04 & 06 & 08\end{array}$ 

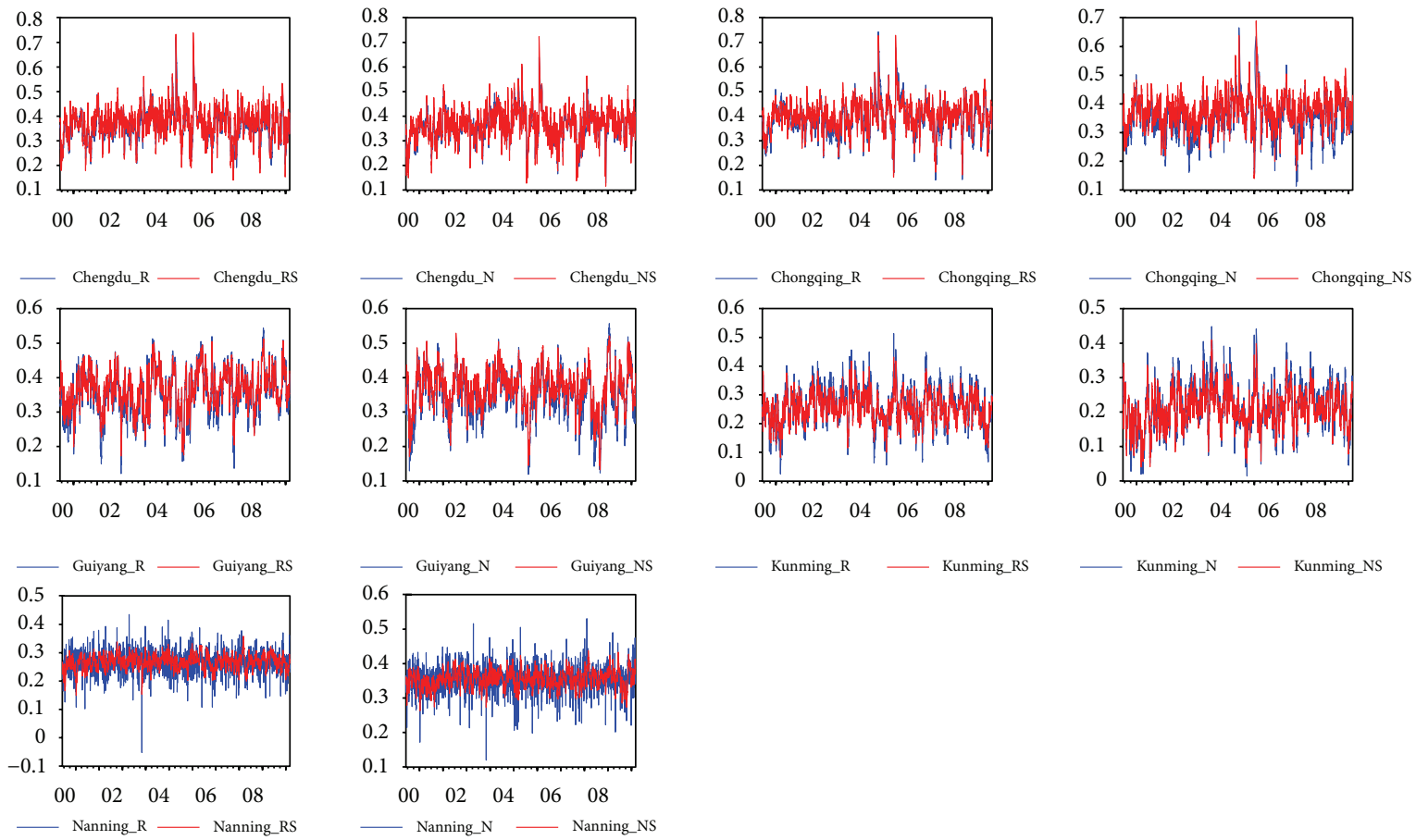

(d)

FIGURE 2: Dynamic correlation comparison. 
mostly between broader regions like countries. Seldom was studied between regions within China, and, in the related research, the integrated APIs were not studied. Up to our knowledge, seasonal variation was studied widely but was mostly focused on the level. Following our previous research [18], by introducing seasonality dummy in the DCC-GARCH model which was an econometric model widely used by many researchers in time-varying correlations finance research, this paper attempts to investigate whether the seasonal effect exists in both first and second moments and how the introduction of seasonal effect affects the dynamic correlations of data series.

This study contributes to the existing literature not only by covering 42 cities of nine regions in China but also by examining both the seasonality of first and second moment and examining their impact on the dynamic correlation between local, regional, and national levels.

The rest of the paper is set up in the following manner. Section 2 presents the econometric model. Section 3 contains the description of the data. The empirical results are in Section 4 , followed by conclusion in the last section.

\section{Model}

Time-varying correlations are often estimated with multivariate GARCH models. Since Bollerslev et al. [19] originally proposed the multivariate GARCH model in the half-vec (vech) form, many others have been developed, but most are linear in squares and cross products of the data [20]. Engle [20] proposed a dynamic conditional correlation (DCC) models which can be estimated very simply with univariate or two-step methods based on the likelihood function. In this paper, we employed the DCC-GARCH model, after Engle [20], to examine the existence of volatility in each series and the dynamic correlations between urban APIs, regional APIs, and national APIs.

Let us consider the APIs $Y_{t}=\left(Y_{1 t}, \ldots, Y_{k t}\right)^{\prime}$, for $t=$ $1, \ldots, T$. The following mean equation was estimated for each series given as

$$
Y_{i t}=\mu_{i}+a Y_{i t-1}+\varepsilon_{i t} \quad \varepsilon_{i t} \sim N\left(0, H_{t}\right),
$$

where $Y_{i t}$ is API in series $i$ at time $t$, and $\varepsilon_{i t}$ is the error term for the API $i$ at time $t$. Equation (1) was then tested for the existence of ARCH. All estimated series exhibited evidence of ARCH effects. The DCC parameterization of conditional covariance metrics is given as [20]

$$
H_{t} \equiv D_{t} R_{t} D_{t}
$$

where $D_{t}$ is the $k \times k$ diagonal matrix of time-varying standard deviations from univariate GARCH models with $\sqrt{h}_{i t}$ on the $i$ th diagonal, and $R_{t}$ is the time-varying correlation matrix.

The elements of $D_{t}$ can be expressed for the univariate form as follows:

$$
h_{i t}=\omega_{i}+\sum_{p=1}^{p_{i}} a_{i p} r_{i t-p}^{2}+\sum_{q=1}^{Q_{i}} \beta_{i q} h_{i t-q}
$$

for $i=1 ; 2, \ldots k$ with the usual GARCH restrictions for nonnegativity and stationarity being imposed, such as nonnegativity of variances and $\sum_{p=1}^{p_{i}} a_{i p}+\sum_{q=1}^{Q_{i}} \beta_{i q}<1$.

The proposed dynamic correlation structure is

$$
\begin{gathered}
Q_{t}=\left(1-\sum_{m=1}^{M} \theta 1_{m}-\sum_{n=1}^{N} \theta 2_{n}\right) \bar{Q}+\sum_{m=1}^{M} \theta 1_{m}\left(\varepsilon_{t-m} \varepsilon_{t-m}^{\prime}\right) \\
+\sum_{n=1}^{N} \theta 2_{n} Q_{t-n}, \\
R_{t}=Q_{t}^{*-1} Q_{t} Q_{t}^{*-1},
\end{gathered}
$$

where $\bar{Q}$ is the unconditional covariance of the standardized residuals resulting from the first-stage estimation and

$$
Q_{t}^{*}=\left[\begin{array}{ccc}
\sqrt{q_{11}} & \cdots & 0 \\
\vdots & \ddots & \vdots \\
0 & \cdots & \sqrt{q_{k k}}
\end{array}\right] \text {, }
$$

so that $Q_{t}^{*}$ is a diagonal matrix composed of the square root of the diagonal elements of $Q_{t}$. The typical element of $R_{t}$ will be of the form $\rho_{i j t}=q_{i j t} / \sqrt{q_{i i} q_{j j}}$.

To investigate the seasonal effect of mean and variance and the effect on the dynamic correlation between local APIs, regional APIs, and national APIs, we set three seasonality dummies in both mean and variance equations, so that (1) now becomes

$$
Y_{i t}=\mu_{i}+S_{2} D_{2}+S_{3} D_{3}+S_{4} D_{4}+a Y_{i t-1}+\varepsilon_{i t} .
$$

Equation (2) becomes

$$
h_{i t}=\omega_{i}+S_{2}^{\prime} D_{2}+S_{3}^{\prime} D_{3}+S_{4}^{\prime} D_{4}+\sum_{p=1}^{p_{i}} a_{i p} r_{i t-p}^{2}+\sum_{q=1}^{Q_{i}} \beta_{i q} h_{i t-q}
$$

so that $D$ is the seasonal effect vector where $D_{2}, D_{3}$, and $D_{4}$ equal 1 , when $t$ is in summer, autumn, or winter, respectively, and other equations are the same. Spring includes March, April, and May; summer includes June, July, and August; autumn includes September, October, and November; winter includes December, January, and February.

\section{Data Description}

The data series for this study comprises of 42 groups of daily average air pollution indexes (APIs) of 42 Chinese sample cities. Each group consists of three series: city API, their corresponding regional level, and national API during the period from June 5, 2000 to March 4, 2010, that is, we have 3560 observations for each series.

Data on urban air pollution index come from the data base of the Ministry of Environmental Protection of China (http://www.zhb.gov.cn/) (MEPPRC). The reason why we choose the 42 sample cities is that even though the APIs of more cities were reported later on, say 87 cities till June, 2011, 
TABle 3: Diagnostic tests.

\begin{tabular}{|c|c|c|c|c|c|c|}
\hline & \multicolumn{3}{|c|}{ Without seasonality dummy } & \multicolumn{3}{|c|}{ With seasonality dummy } \\
\hline & $\log (\mathrm{L})$ & AIC & $\mathrm{BC}$ & $\log (\mathrm{L})$ & AIC & $\mathrm{BC}$ \\
\hline \multicolumn{7}{|c|}{ (A) Central China } \\
\hline Changsha, regional, and national & -40025.2 & 22.50 & 22.53 & -39361.9 & 22.14 & 22.20 \\
\hline Hefei, regional, and national & -41104.9 & 23.10 & 23.14 & -40345.2 & 22.69 & 22.76 \\
\hline Nanchang, regional, and national & -39886.3 & 22.42 & 22.45 & -39360.6 & 22.13 & 22.20 \\
\hline Wuhan, regional, and national & -39781.4 & 22.36 & 22.40 & -38801.2 & 21.82 & 21.89 \\
\hline Zhenzhou, regional, and national & -42877.7 & 24.10 & 24.13 & -42039.1 & 23.64 & 23.71 \\
\hline \multicolumn{7}{|c|}{ (B) East China } \\
\hline Hangzhou, regional, andnational & -37091.9 & 20.85 & 20.88 & -36269.1 & 20.40 & 20.47 \\
\hline Jinan, regional, and national & -43761.2 & 24.60 & 24.63 & -42476.7 & 23.89 & 23.95 \\
\hline Nanjing, regional, and national & -41336.6 & 23.23 & 23.27 & -40413.4 & 22.73 & 22.79 \\
\hline Nantong, regional, and national & -34871.4 & 19.60 & 19.64 & -33939.7 & 19.09 & 19.16 \\
\hline Qingdao, regional, and national & -39897.2 & 22.43 & 22.46 & -38419 & 21.61 & 21.67 \\
\hline Shanghai, regional, and national & -35204.1 & 19.79 & 19.82 & -34261.7 & 19.27 & 19.34 \\
\hline Suzhou, regional, and national & -33960.4 & 19.09 & 19.12 & -34161.5 & 19.21 & 19.28 \\
\hline Wenzhou, regional, and national & -38456 & 21.62 & 21.65 & -37964.4 & 21.35 & 21.42 \\
\hline Yantai, regional, and national & -41609.3 & 23.39 & 23.42 & -39981.2 & 22.48 & 22.55 \\
\hline \multicolumn{7}{|c|}{ (C) North China } \\
\hline Beijing, regional, and national & -42467.6 & 23.87 & 23.90 & -41407.5 & 23.28 & 23.35 \\
\hline Huhehaote, regional, and national & -43935.3 & 24.69 & 24.73 & -42821.3 & 24.08 & 24.15 \\
\hline Shijiazhuang, regional, and national & -43343.2 & 24.36 & 24.40 & -42522.7 & 23.91 & 23.98 \\
\hline Taiyuan, regional, and national & -43172.6 & 24.27 & 24.30 & -42804.1 & 24.07 & 24.14 \\
\hline Tianjin, regional, and national & -43504.4 & 24.45 & 24.49 & -42123.2 & 23.69 & 23.75 \\
\hline \multicolumn{7}{|c|}{ (D) Northeast } \\
\hline Changchun, regional, and national & -40528.1 & 22.78 & 22.81 & -38723.9 & 21.78 & 21.84 \\
\hline Dalian, regional, and national & -44462.8 & 24.99 & 25.03 & -42930.7 & 24.14 & 24.21 \\
\hline Haerbin, regional, and national & -41494.3 & 23.32 & 23.36 & -39461.6 & 22.19 & 22.26 \\
\hline Shenyang, regional, and national & -42282.4 & 23.77 & 23.80 & -40886.8 & 22.99 & 23.06 \\
\hline \multicolumn{7}{|c|}{ (E) Northwest } \\
\hline Lanzhou, regional, and national & -48028.2 & 26.99 & 27.03 & -45529.5 & 25.60 & 25.67 \\
\hline Xian, regional, and national & -45313.9 & 25.47 & 25.50 & -43805.4 & 24.63 & 24.70 \\
\hline Yinchuan, regional, and national & -45947 & 25.82 & 25.86 & -43833.9 & 24.65 & 24.72 \\
\hline Wulumuqi, regional, and national & -46248.1 & 25.99 & 26.03 & -44306.9 & 24.91 & 24.98 \\
\hline \multicolumn{7}{|c|}{ (F) Qinghai-Tibet } \\
\hline Lasa, regional, and national & -43834.8 & 24.64 & 24.67 & -42628.7 & 23.97 & 24.04 \\
\hline Xining, regional, and national & -48225.4 & 27.10 & 27.14 & -46366.3 & 26.07 & 26.14 \\
\hline \multicolumn{7}{|c|}{ (G) South China } \\
\hline Guangzhou, regional, and national & -33688.9 & 18.94 & 18.97 & -33282.6 & 18.72 & 18.79 \\
\hline Shenzhen, regional, and national & -31382.8 & 17.64 & 17.68 & -30890.8 & 17.38 & 17.44 \\
\hline Zhuhai, regional, and national & -31246.1 & 17.57 & 17.60 & -30971.2 & 17.42 & 17.49 \\
\hline Zhanjiang, regional, and national & -30018.4 & 16.88 & 16.91 & -29767.6 & 16.75 & 16.81 \\
\hline Haikou, regional, and national & -30034.8 & 16.88 & 16.92 & -29682.4 & 16.70 & 16.77 \\
\hline \multicolumn{7}{|c|}{ (H) Southeast } \\
\hline Fuzhou, regional, and national & -39521.7 & 22.21 & 22.25 & -39112.6 & 22.00 & 22.06 \\
\hline Shantou, regional, and national & -37615.6 & 21.14 & 21.18 & -37231.3 & 20.94 & 21.01 \\
\hline
\end{tabular}


TABLE 3: Continued.

\begin{tabular}{|c|c|c|c|c|c|c|}
\hline & \multicolumn{3}{|c|}{ Without seasonality dummy } & \multicolumn{3}{|c|}{ With seasonality dummy } \\
\hline & $\log (\mathrm{L})$ & AIC & $\mathrm{BC}$ & $\log (\mathrm{L})$ & AIC & $\mathrm{BC}$ \\
\hline Xiamen, regional, and national & -36573 & 20.56 & 20.59 & -36170.9 & 20.34 & 20.41 \\
\hline \multicolumn{7}{|c|}{ (I) Southwest } \\
\hline Chengdu, regional, and national & -40856.3 & 22.96 & 23.00 & -40074.7 & 22.54 & 22.60 \\
\hline Chongqing, regional, and national & -40428.6 & 22.72 & 22.76 & -39840.6 & 22.40 & 22.47 \\
\hline Guiyang, regional, and national & -38606.5 & 21.70 & 21.74 & -38228.3 & 21.50 & 21.57 \\
\hline Kunming, regional, and national & -37677.7 & 21.18 & 21.21 & -37317.2 & 20.99 & 21.05 \\
\hline Nanning, regional, and national & -37909.9 & 21.31 & 21.34 & -37633.2 & 21.16 & 21.23 \\
\hline
\end{tabular}

Notes: This table exhibits the comparison between DCC estimation without and with seasonality dummies. $\log (\mathrm{L})$ denotes Log-likelihood; AIC and BC denote Akaike and Schwarz information criteria, respectively.

the data of these 42 cities were available since June 5, 2000, so we have more observation; moreover, the 42 cities were scattered in the nine regions of China (shown in Table 1). Based on the climate type, regional geographical features, and so forth, there are many ways of Chinese regional divisions. According to Zhen Du et al. [21], Lin Chao, Luo Kaifu, Huang Bingwei, Ren Meie, Zhao Xueyu, Zhao Songqiao, Xi Chengfan, and so forth suggested different schemes. We employed the scheme which is based on the division of Ren Meie and Yang Renzhang.

The data of regional and national levels are integrated from APIs of the other cities within the region and nation, respectively, by calculating inverse distance weighted the average of city APIs for all the other cities in the region and in the nation.

Figure 1 presents the plot of APIs for 42 sample cities and corresponding regional and national levels. These plots are similar in all 126 series, obvious volatility clustering feature can be noticed. Even though, except for few series, seasonal variation of raw data can be noticed, unit root tests exhibit that only the ADF unit root tests without constant and trend of few series are not statistically significant; ADF test of most series and PP test show that all the series are statistically significant, rejecting the hypothesis that there exist unit roots.

\section{Results}

Table 2 reports the estimation result of the two-step DCCGARCH model based on the univariate GARCH $(1,1)$ for each series. All the estimates in this paper are obtained using the OxMetrics 5.10 econometric software package developed by Jurgen A. Doornik. The error student distribution assumption has been used in all cases.

In the mean equations, the $c$ and $\mathrm{AR}$ estimations are all significant at $1 \%$ level; except 17 out of 126 series, the $\operatorname{ARCH}(\alpha)$ estimations are significant at 5\% level. Except 7 out of 126 series, the $\operatorname{GARCH}(\beta)$ estimation is significant at least at $5 \%$ level. Except for the $\theta_{1}$ estimations of Beijing and Taiyuan, the estimations of DCC parameters, $\theta_{1}$ and $\theta_{2}$, are statistically significant at $5 \%$ level in all left 40 cases. This indicates that the assumption of constant conditional correlation for all shocks to return is not supported empirically. Except for Tianjin, the short-run persistence of shocks on the dynamic conditional correlations is low, under 0.1 generally, while the long-run persistence of shocks to the conditional correlations is high for most sample cities.

As shown in Table 3, from the results of the tests, the model with seasonality dummies outperform the one without seasonality dummies according to all three criteria, say the $\log (\mathrm{L}), \mathrm{AIC}$, and BC.

Table 4 reports the seasonality dummies significance of mean equations and variance equations. The result exhibits both general rules and regional heterogeneity. In general, the seasonality feature of the second moment follows that of the first moment, specifically, if summer is significantly lower than spring in the mean equation, the situation is mostly the same in the variance equation, but, except southern China, when the conditional mean in winter is significantly higher than spring, the variance equation does not follow the same feature. In almost all cities and regions, the condition mean and variance of summer are significantly lower than spring. In several regions, the condition mean and variance of winter are significantly higher than spring.

Focusing on the regional level, Central China, northern China, northwest, northeast, southeast and Southwest exhibit same features, both the conditional mean and the conditional variance of the second and autumn are lower than that of spring, whereas winter is higher than spring; for the QinghaiTibet and southern China, both the conditional mean and the conditional variance of the second and autumn are lower than that of spring, where as winter is not significantly different than spring; southern China, which is composed of three cities in Fujian province, is a special one, with both the conditional mean and the conditional variance of summer lower than that of spring, and the third and fourth seasons are higher than spring.

Figure 2 presents the time-varying conditional correlations between sample cities and their corresponding regional and national levels. The blue lines are the dynamic correlations calculated from DCC-GARCH models without seasonality dummies, while the red lines are from the ones with seasonality dummies. It is clear that there is significant variation in the conditional correlations over time; most sample cities exhibit similar dynamic correlations with what is calculated from DCC-GARCH models without seasonality dummies (blue lines). Northwest and Qinghai-Tibet exhibit 
TABLE 4: Seasonality significance.

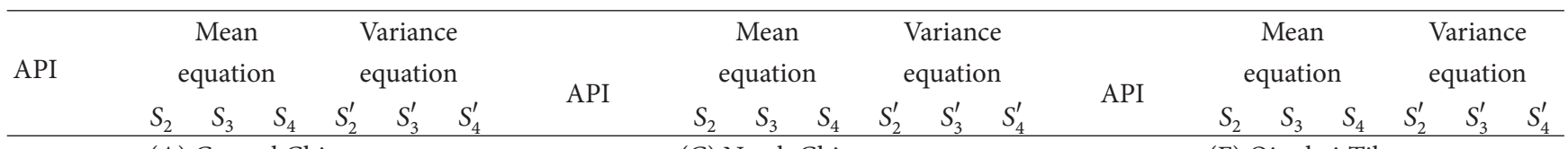

\section{(A) Central China}

Changsha, regional, and national

Changsha -

Regional - -

National $-\quad+\quad+$

Hefei, regional, and national

Hefei

Regional

National +

Nanchang, regional, and national

Nanchang -

Regional -

National $\quad-\quad+\quad$

Wuhan, regional, and national

Wuhan

Regional - $\quad-\quad-$

National $-c_{1}+c_{-}$

Zhenzhou, regional, and national

Zhenzhou - - +

Regional - $\quad-\quad$

National $\quad-\quad+\quad+\quad-$

(B) East China

Hangzhou, regional, and national

Hangzhou -

Regional - -

National $\quad-\quad-\quad-\quad \begin{array}{lll} & - & -\end{array}$

Jinan, regional, and national

Jinan

National - $\quad+\quad-$

Nanjing, regional, and national

Nanjing - $\quad-\quad$ -

Regional - $\quad-\quad-\quad \begin{array}{lll}- & -\end{array}$

National $\quad-\quad-\quad-\quad-\quad-$

Nantong, regional, and national

Nantong - $\quad$ -

Regional - -

National - $\quad$ -

Qingdao, regional, and national

Qingdao $\quad-\quad-\quad+\quad-\quad-$

Regional - $-\begin{array}{lllll} & - & & - & -\end{array}$

National $\quad-\quad-\quad+\quad-\quad-$

Shanghai, regional, and national

Shanghai

(C) North China

Beijing, regional, and national

(F) Qinghai-Tibet

Xining, regional, and national

Beijing

Regional

National

Huhehaote, regional, and national

Huhehaote

Regional - +

National $\quad-\quad-\quad+\quad-$

Shijiazhuang, regional, and national Shijiazhuang $-\quad-\quad+\quad-$

Regional - +

National $\quad-\quad-\quad+\quad-$

Taiyuan, regional, and national

Taiyuan

Regional

National $-\quad-\quad+\quad-\quad$

Tianjin, regional, and national

Tianjin

Regional

National

(D) Northeast

Changchun, regional, and national

Changchun $-\quad-\quad+$

Regional - $\quad-\quad+$

National $-\quad-\quad+\quad-$

Dalian, regional, and national

Dalian

Regional $-\quad-\quad+\quad-\quad$

National $\quad-\quad-\quad+\quad-\quad$

Haerbin, regional, and national

Haerbin - +

Regional $\quad-\quad-\quad+$

National $\quad-\quad-\quad+$

Shenyang, regional, and national

Shenyang $-\quad-\quad+\quad-$

Regional _ - $\quad+$

National _ $\quad-\quad+$

(E) Northwest

Lanzhou, regional, and national

Lanzhou

Regional _ $\quad-\quad-\quad+$

National $\quad-\quad+$

Xian, regional, and national

\section{Xining}

Regional

National

(G) South China

Guangzhou, regional, and national

Guangzhou

Regional

National $\quad-\quad+\quad+\quad-\quad+$

Shenzhen, regional, and national

Shenzhen -++

Regional $\quad-\quad+\quad+\quad-\quad-$

National $\quad-\quad+\quad+\quad-\quad-$

Zhuhai, regional, and national

Zhuhai

Regional $-\quad+\quad+\quad-\quad-\quad+$

National $-+\quad+\quad-\quad-\quad+$

Zhanjiang, regional, and national

Zhanjiang

Regional $-\quad+\quad+$

National $\quad-\quad+\quad+\quad-\quad \begin{array}{lll}+ & +\end{array}$

Haikou, regional, and national

Haikou

Regional -+++

National -++++

(H) Southeast

Fuzhou, regional, and national

Fuzhou - - -

Regional $-C_{-}+-$

National - $\quad+$

Shantou, regional, and national

Shantou

Regional

National

Xiamen, regional, and national

Xiamen

Regional

National

(I) Southwest

Chengdu, regional, and national

Chengdu

Regional $-\quad-\quad+\quad-$

National $\quad-\quad+\quad+\quad$ 
TABLE 4: Continued.

\begin{tabular}{|c|c|c|c|c|c|c|c|c|c|c|c|c|c|c|c|c|c|c|c|c|}
\hline \multirow[t]{2}{*}{ API } & \multicolumn{3}{|c|}{$\begin{array}{c}\text { Mean } \\
\text { equation }\end{array}$} & \multicolumn{3}{|c|}{$\begin{array}{l}\text { Variance } \\
\text { equation }\end{array}$} & \multirow{2}{*}{ API } & \multicolumn{3}{|c|}{$\begin{array}{c}\text { Mean } \\
\text { equation }\end{array}$} & \multicolumn{3}{|c|}{$\begin{array}{l}\text { Variance } \\
\text { equation }\end{array}$} & \multirow{2}{*}{ API } & \multicolumn{3}{|c|}{$\begin{array}{c}\text { Mean } \\
\text { equation }\end{array}$} & \multicolumn{3}{|c|}{$\begin{array}{l}\text { Variance } \\
\text { equation }\end{array}$} \\
\hline & $S_{2}$ & $S_{3}$ & $S_{4}$ & $S_{2}^{\prime}$ & $S_{3}^{\prime}$ & $S_{4}^{\prime}$ & & $S_{2}$ & $S_{3}$ & $S_{4}$ & $S_{2}^{\prime}$ & $S_{3}^{\prime}$ & $S_{4}^{\prime}$ & & $S_{2}$ & $S_{3}$ & $S_{4}$ & $S_{2}^{\prime}$ & $S_{3}^{\prime}$ & $S_{4}^{\prime}$ \\
\hline Regional & - & - & & - & - & & Xian & & & + & & & & \multicolumn{7}{|c|}{ Chongqing, regional, and national } \\
\hline National & - & - & & - & & & Regional & - & - & + & - & - & & Chongqing & - & - & + & - & - & \\
\hline \multicolumn{7}{|c|}{ Suzhou, regional, and national } & National & - & - & + & & & & Regional & - & - & + & & & \\
\hline Suzhou & - & - & & - & & & \multicolumn{7}{|c|}{ Yinchuan, regional, and national } & National & - & & + & - & - & \\
\hline Regional & - & - & & & & & Yinchuan & - & - & + & & & & \multicolumn{7}{|c|}{ Guiyang, regional, and national } \\
\hline National & - & & & - & - & & Regional & - & - & & - & - & & Guiyang & - & & + & & & \\
\hline \multicolumn{7}{|c|}{ Wenzhou, regional, and national } & National & - & - & + & - & - & & Regional & - & - & + & - & - & \\
\hline Wenzhou & - & - & - & - & - & & \multicolumn{7}{|c|}{ Wulumuqi, regional, and national } & National & - & & + & - & - & \\
\hline Regional & - & - & & - & & & Wulumuqi & - & & + & & & & \multicolumn{7}{|c|}{ Kunming, regional, and national } \\
\hline National & - & - & & & & & Regional & - & - & + & - & - & & Kunming & - & - & + & & & \\
\hline \multicolumn{7}{|c|}{ Yantai, regional, and national } & National & - & - & + & & & & Regional & - & & + & & & \\
\hline Yantai & - & - & & - & - & - & \multicolumn{7}{|c|}{ Panel F: Qinghai-Tibet } & National & - & & + & & & \\
\hline Regional & - & - & + & - & - & - & \multicolumn{7}{|c|}{ Lasa, regional, and national } & \multicolumn{7}{|c|}{ Nanning, regional, and national } \\
\hline \multirow[t]{3}{*}{ National } & - & - & + & - & - & & Lasa & - & - & & - & & + & Nanning & - & + & + & - & & + \\
\hline & & & & & & & Regional & - & - & + & - & - & - & Regional & - & - & + & - & & \\
\hline & & & & & & & National & - & - & + & & & & National & - & & + & & & + \\
\hline
\end{tabular}

Notes: $S_{2}, S_{3}, S_{4}$ and $S_{2}^{\prime}, S_{3}^{\prime}, S_{4}^{\prime}$ denote summer, autumn, and winter, respectively. - + + denote the negative and positive signs of the coefficients of seasonality dummies which were significant at $5 \%$ level. The empty entries mean that the corresponding coefficients are not significant at $5 \%$ level.

low-average relation with regional and national APIs, while East China, North China, and southeast exhibit high relation. Wulumuqi and Lasa exhibit very low relation with regional and national APIs; Xining shows a high relation with national but a low relation with regional API, indicating that cities in vast territory and special terrain are not very sensitive to shocks of regional and national APIs. Several cities exhibit special characters. Zhenzhou has almost zero short-run persistence of shocks to the conditional correlations $\left(\Theta_{1}\right)$ in model with seasonality dummies and exhibits constant correlation accordingly. For Taiyuan, including seasonality dummies decreases the variance of dynamic correlations. Shenzhen and Zhuhai, the two cities with the shortest distance between each other, exhibit a decrease of dynamic correlation with both regional and national levels after spring 2001 and then an increase again after autumn 2004 and reach a relative stable level in summer 2006. Southeast and Qinghai-Tibet exhibit obvious seasonal variation.

\section{Discussion}

Understanding how the mean and variance of the APIs change across season and whether there exists the regional homogeneity concerning seasonality is important in understanding the features of the city APIs and the regional nature of APIs. Tracing the dynamic correlations of city APIs and regional/ national levels is a crucial issue for the understanding of the space relationship of APIs and policy implications. Following our previous study, this paper has investigated the seasonality of the first and the second moments of 42 sample Chinese cities scattered in nine regions. Then, dynamic correlations of 42 sample cities' APIs with the regional and national APIs are investigated; comparison with the ones we got from the model without considering the seasonality is made.

The main results can be summarized in the following several aspects. About the model specification, even though some seasonality dummies are not significant, including the seasonality dummies in the mean and variance equations has improved the model in terms of log-likelihood, AIC, and $\mathrm{BC}$ criteria. About the seasonality, seasonality feature of the second moment follows that of the first moment. In most cities and regions, the condition mean and variance of the second and autumn are significantly lower than spring, whereas that of winter is higher than spring. That means that the spring and winter exhibit not only the highest mean but also the highest variance of API. Previous studies found that TSP, PM10, PM2.5, surface $\mathrm{O}_{3}, \mathrm{SO}_{2}, \mathrm{NO}_{2}$, and $\mathrm{NH}_{3}$ are observed higher in winter, and our result found that API (integrated from the observation of three pollutant: reparable particulate matter (PM10), $\mathrm{SO}_{2}$, and nitrogen dioxide $\left(\mathrm{NO}_{2}\right)$ ), an integrated index, also exhibits the same seasonal variation. About the regional features, Qinghai-Tibet, South China, and Southeast China exhibit special features concerning the seasonality effect. Turning to the dynamic correlations, the dynamic correlations calculated from the seasonality dummies are different from that of the model without seasonality dummies, they are time varying, and moreover they exhibit the same features, indicating that including the seasonality dummies in DCC-GARCH models improved the model estimation, while it did not influence the feature of the dynamic correlations very much. 


\section{Conclusions}

These results have strong policy implications. When capturing the regional and interregional relationship, seasonal variation should be taken into consideration. Spring and winter exhibit higher volatility, which means higher uncertainty; regional or single city settlement in air pollution control is important but not enough, and interregional cooperation and national decision are important. The cooperation mechanism should be able to respond. the time-varying nature of conditional correlation; regional heterogeneity should be considered in cooperation policy decision; cooperation among regions with higher correlation and similar correlation feature is better.

The limitations of this study are that the data can be improved in the future when more important observations of air quality like PM2.5 are detected and integrated in the API; moreover, the approximation of national API can be improved, and comparison between other possible divisions of region can be made in the future study.

\section{References}

[1] P. J. Miller and J. Grumet, "Bi-national and regional issues in air quality science and policy," Environmental Science and Policy, vol. 1, no. 3, pp. 223-230, 1998.

[2] F. Cousin, P. Tulet, and R. Rosset, "Interaction between local and regional pollution during Escompte 2001: impact on surface ozone concentrations (IOP2a and 2b)," Atmospheric Research, vol. 74, no. 1-4, pp. 117-137, 2005.

[3] F. Xiao, V. Brajer, and R. W. Mead, "Blowing in the wind: the impact of China's Pearl River Delta on Hong Kong's air quality," Science of the Total Environment, vol. 367, no. 1, pp. 96-111, 2006.

[4] Y. Zhang, S. C. Olsen, and M. K. Dubey, "WRF/Chem simulated springtime impact of rising Asian emissions on air quality over the U.S.", Atmospheric Environment, vol. 44, no. 24, pp. 27992812, 2010.

[5] T. Holloway, T. Sakurai, Z. Han et al., "MICS-Asia II: impact of global emissions on regional air quality in Asia," Atmospheric Environment, vol. 42, no. 15, pp. 3543-3561, 2008.

[6] Y. C. Lee, X. Yang, and M. Wenig, "Transport of dusts from East Asian and non-East Asian sources to Hong Kong during dust storm related events 1996-2007," Atmospheric Environment, vol. 44, no. 30, pp. 3728-3738, 2010.

[7] C. M. Liu, C. Y. Young, and Y. C. Lee, "Influence of Asian dust storms on air quality in Taiwan," Science of the Total Environment, vol. 368, no. 2-3, pp. 884-897, 2006.

[8] X. X. Zhang, P. J. Shi, L. Y. Liu et al., "Ambient TSP concentration and dustfall in major cities of China: spatial distribution and temporal variability," Atmospheric Environment, vol. 44, no. 13, pp. 1641-1648, 2010.

[9] G. Grivas, A. Chaloulakou, and P. Kassomenos, "An overview of the PM10 pollution problem, in the Metropolitan Area of Athens, Greece. Assessment of controlling factors and potential impact of long range transport," Science of the Total Environment, vol. 389, no. 1, pp. 165-177, 2008.

[10] K. Yamaji, T. Ohara, I. Uno, H. Tanimoto, J. I. Kurokawa, and H. Akimoto, "Analysis of the seasonal variation of ozone in the boundary layer in East Asia using the community multiscale air quality model: what controls surface ozone levels over
Japan?" Atmospheric Environment, vol. 40, no. 10, pp. 1856-1868, 2006.

[11] G. C. Fang and S. C. Chang, "Atmospheric particulate (PM10 and PM2.5) mass concentration and seasonal variation study in the Taiwan area during 2000-2008," Atmospheric Research, vol. 98, no. 2-4, pp. 368-377, 2010.

[12] J. Zheng, L. Zhong, T. Wang, P. K. K. Louie, and Z. Li, "Groundlevel ozone in the Pearl River Delta region: analysis of data from a recently established regional air quality monitoring network," Atmospheric Environment, vol. 44, no. 6, pp. 814-823, 2010.

[13] L. Y. Chan and W. S. Kwok, "Roadside suspended particulates at heavily trafficked urban sites of Hong Kong-seasonal variation and dependence on meteorological conditions," Atmospheric Environment, vol. 35, no. 18, pp. 3177-3182, 2001.

[14] K. L. So, H. Guo, and Y. S. Li, "Long-term variation of PM2.5 levels and composition at rural, urban, and roadside sites in Hong Kong: increasing impact of regional air pollution," Atmospheric Environment, vol. 41, no. 40, pp. 9427-9434, 2007.

[15] S. Hoti, M. McAleer, and F. Chan, "Modelling the spillover effects in the volatility of atmospheric carbon dioxide concentrations," Mathematics and Computers in Simulation, vol. 69, no. 1-2, pp. 46-56, 2005.

[16] K. L. Yang, "Spatial and seasonal variation of PM10 mass concentrations in Taiwan," Atmospheric Environment, vol. 36, no. 21, pp. 3403-3411, 2002.

[17] A. K. Gupta, K. Karar, S. Ayoob, and K. John, "Spatio-temporal characteristics of gaseous and particulate pollutants in an urban region of Kolkata, India," Atmospheric Research, vol. 87, no. 2, pp. 103-115, 2008.

[18] H. Zhanqiong, S. Sriboonchitta, P. Calkins, A. Wiboonpongse, and P. Leeahtam, "Air pollution uncertainty modelling based on urban API: a case of Beijing, China," Thailand Econometrics Society, vol. 3, no. 3, pp. 247-257, 2011.

[19] T. Bollerslev, R. F. Engle, and J. M. Wooldridge, "A capital asset pricing model with time varying covariances," Journal of Political Economy, vol. 96, pp. 116-131, 1988.

[20] R. Engle, "Dynamic conditional correlation: a simple class of multivariate generalized autoregressive conditional heteroskedasticity models," Journal of Business and Economic Statistics, vol. 20, no. 3, pp. 339-350, 2002.

[21] D. Zheng, Q. Ge, X. Zhang, F. He, S. Wu, and Q. Yang, "Regionalization in China: retrospect and prospect," Geographical Research, vol. 24, no. 3, pp. 330-344, 2005 (Chinese). 

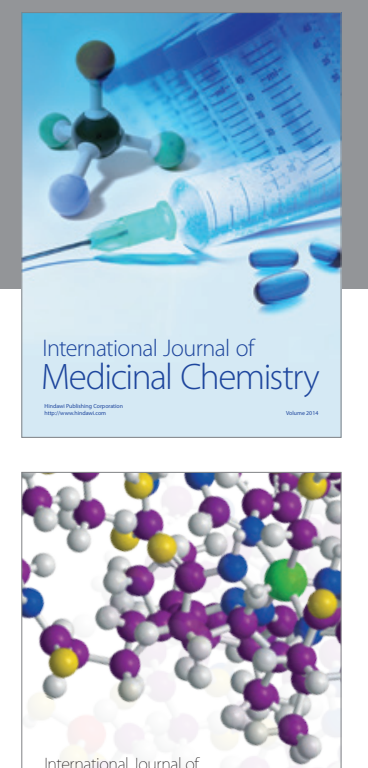

\section{Carbohydrate} Chemistry

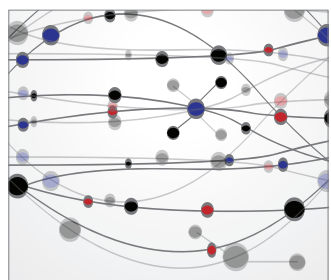

The Scientific World Journal
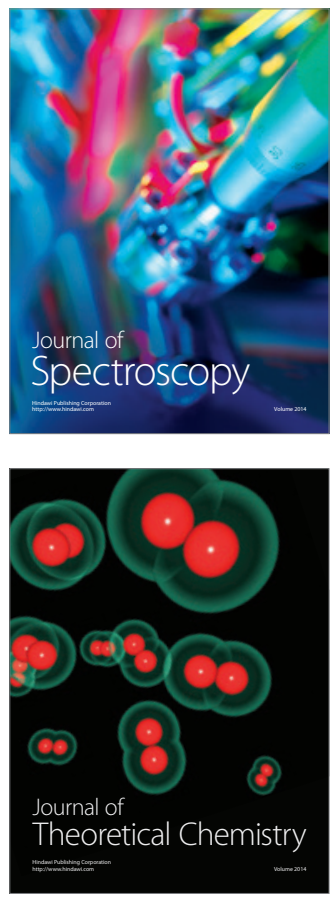
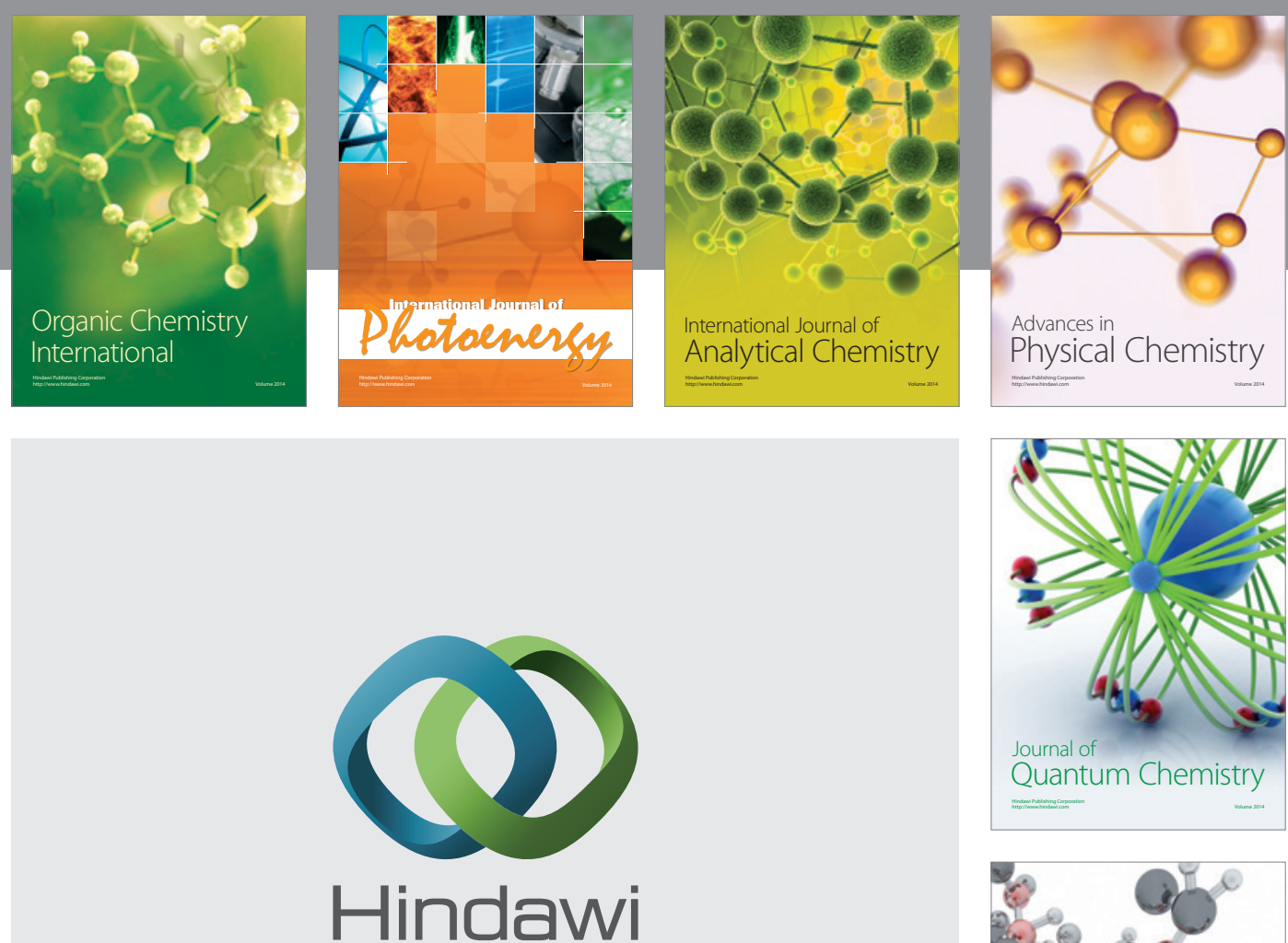

Submit your manuscripts at

http://www.hindawi.com

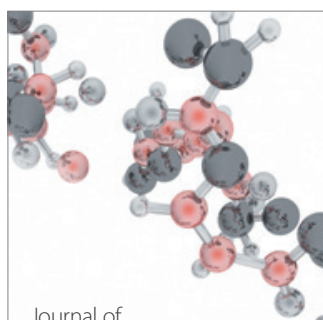

Analytical Methods

in Chemistry

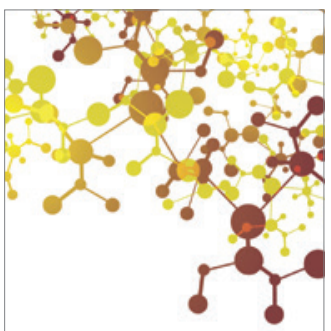

Journal of

Applied Chemistry

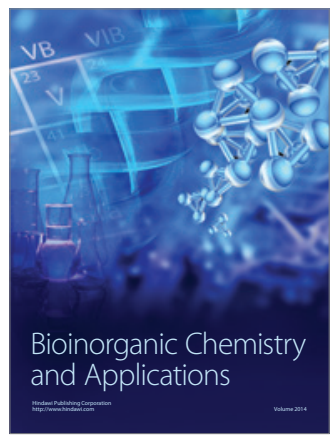

Inorganic Chemistry
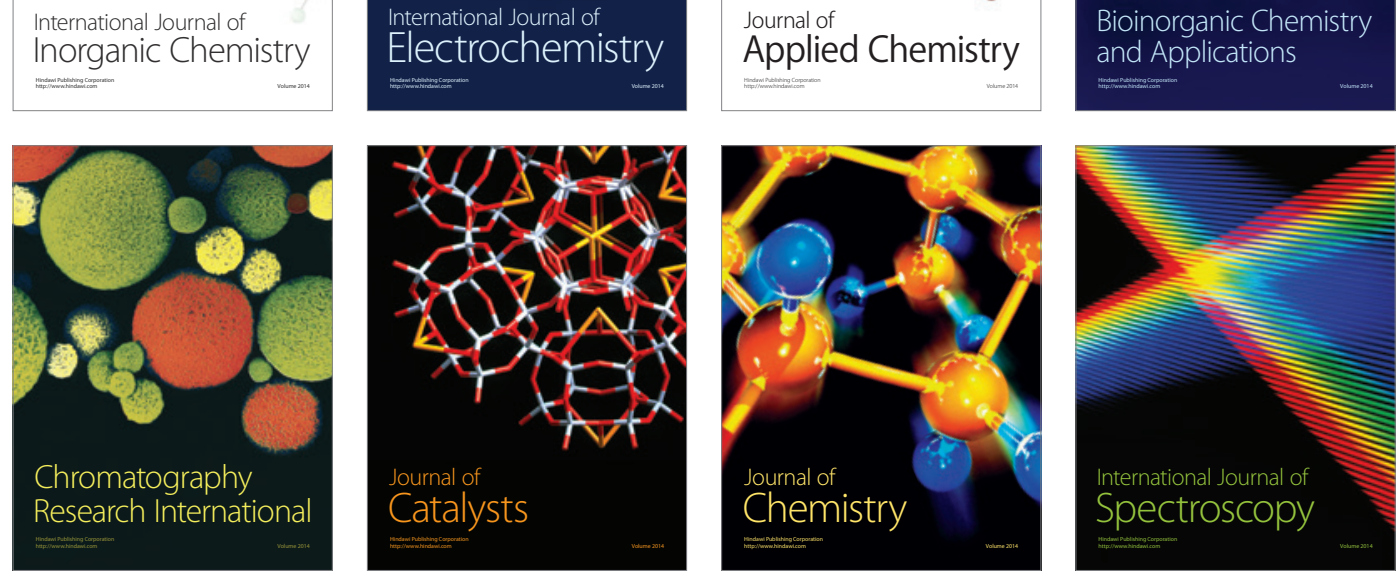